(2) Open Access Full Text Article

\title{
Strategies to Improve Photodynamic Therapy Efficacy of Metal-Free Semiconducting Conjugated Polymers
}

\author{
Na Sun' \\ Xue Wen ${ }^{2}$ \\ Song Zhang $\mathbb{B D}^{1}$ \\ 'Department of Nuclear Medicine, \\ XinQiao Hospital, Army Medical \\ University, Chongqing, People's Republic \\ of China; ${ }^{2}$ School of Electronics, \\ Information and Electrical Engineering, \\ Shanghai Jiao Tong University, Shanghai, \\ People's Republic of China
}

\begin{abstract}
Photodynamic therapy (PDT) is a noninvasive therapy for cancer and bacterial infection. Metal-free semiconducting conjugated polymers $\left(\mathrm{SCP}_{\mathrm{S}}\right)$ with good stability and optical and electrical properties are promising photosensitizers (PSs) for PDT compared with traditional small-molecule PSs. This review analyzes the latest progress of strategies to improve PDT effect of linear, planar, and three-dimensional $\mathrm{SCP}_{\mathrm{S}}$, including improving solubility, adjusting conjugated structure, enhancing PS-doped SCPs, and combining therapies. Moreover, the current issues, such as hypoxia, low penetration, targeting and biosafety of $\mathrm{SCP}_{\mathrm{S}}$, and corresponding strategies, are discussed. Furthermore, the challenges and potential opportunities on further improvement of PDT for SCPs are presented.
\end{abstract}

Keywords: semiconducting conjugated polymers, photosensitizer, photodynamic therapy, enhancing phototherapy strategies

\section{Introduction}

Photodynamic therapy (PDT) is a noninvasive treatment method that can prevent several side effects of chemotherapy and radiotherapy. PDT interferes with the balance between reactive oxygen species (ROS) generation and detoxification by selecting the appropriate wavelength of light-activated PSs and destroys the components of cancer cells. Traditional photosensitizers (PSs) are small organic molecules that usually have short excitation wavelength, low structural stability, and poor solubility. ${ }^{1}$ Therefore, $\mathrm{SCP}_{\mathrm{S}}$ with light-harvesting capability to absorb visible light and near-infrared (NIR) and efficient energy transfer due to its delocalized p-system ${ }^{2-4}$ have been actively developed. $\mathrm{SCP}_{\mathrm{S}}$ have a conjugated structure and high stability, and its boundary contains hydrophilic groups, which has good biocompatibility ${ }^{5}$ and essentially prevents the toxic side effects of heavy metal ions and small molecules on the organism compared with inorganic semiconductors $\mathrm{TiO}_{2},{ }^{6} \mathrm{ZnSe} / \mathrm{ZnS},{ }^{7}$ and CdSe. ${ }^{8}$ These properties promote the application of $\mathrm{SCP}_{\mathrm{S}}$ in the biomedical field, such as fluorescence imaging, ${ }^{9-11}$ PDT, $^{12,13}$ photothermal therapy (PTT), ${ }^{14,15}$ and antibacterial application. ${ }^{16,17}$

\section{Brief History of PDT Based on SCP}

The groundbreaking report on conjugated polymer PDT can be traced back to the study by Ikada in 1997. Under light irradiation, PEG-fullerene $\mathrm{C}_{60}$ may successfully create singlet oxygen $\left({ }^{1} \mathrm{O}_{2}\right) .{ }^{18}$ However, fullerene has low solubility and activity, resulting in 
the delayed development of SCPs for PDT. Carbon-based nanomaterials, such as graphene quantum dots (GQDs) and graphitic carbon nitride $\left(\mathrm{g}-\mathrm{C}_{3} \mathrm{~N}_{4}\right)$, have the advantages of chemical inertness, ease of operation, high photostability, and good biocompatibility. ${ }^{19-22}$ These materials' electronic bands are analogous to conductive metals, and their chemical composition and electronic structure are highly adjustable. ${ }^{23}$ In the last 10 years, many types of $\mathrm{SCP}_{\mathrm{S}}$ have emerged, such as polypyrrole, ${ }^{24}$ polythiophene, ${ }^{25}$ poly (cyclopentadithiophene, benzothiadiazole), ${ }^{26}$ polyfluorene, ${ }^{27}$ porphyrin-based covalent organic framework (COF). ${ }^{28}$ The historical development of $\mathrm{SCP}_{\mathrm{S}}$ in PDT is shown in Figure 1.

\section{Basic Principle of SCPs in PDT}

Generally, PSs in the ground singlet state $\left(\mathrm{S}_{0}\right)$ can be excited to the first excited singlet state $\left(\mathrm{S}_{1}\right)$ under light irradiation and then go through the intersystem crossing (ISC) to reach the first excited triplet state $\left(T_{1}\right)$. PSs at $T_{1}$ can directly interact with the substrate to generate ROS and induce tumor tissue destruction through apoptosis or necrosis, vascular injury, and inflammation-mediated immune response.
Based on photophysics and photochemistry, PDT can be divided into type I and II PDT (Figure 2A).

For type I PDT, electron transfer or hydrogen abstraction between PSs and substrate generate short-lived free radicals, which then immediately react with molecules, such as water and oxygen, to generate hydrogen peroxide $\left(\mathrm{H}_{2} \mathrm{O}_{2}\right)$, superoxide radical $\left(\mathrm{O}_{2}{ }^{\circ-}\right)$, and hydroxyl radical $(\bullet \mathrm{OH}){ }^{1,29} \mathrm{SCP}_{\mathrm{S}}$ with denser orbits show the lowest unoccupied molecular orbital (LUMO) and highest occupied molecular orbital (HOMO) levels. HOMO and LUMO represent the valence band maximum and conduction band minimum, respectively, of inorganic semiconductors (Figure 2B). ${ }^{30}$ The release of $\operatorname{ROS}\left(\mathrm{O}_{2}{ }^{\cdot-}, \cdot \mathrm{OH}\right)$ from water by $\mathrm{SCP}_{\mathrm{S}}$ involves two parallel reactions: reduction reaction and oxidation reaction. First, the incident light energy is greater than the bandgap of $\mathrm{SCP}_{\mathrm{S}}$, which can be excited. Second, the lower edge of the conduction band $\left(\mathrm{E}_{\mathrm{C}}\right)$ and upper edge of the valence band $\left(\mathrm{E}_{\mathrm{V}}\right)$ of $\mathrm{SCP}_{\mathrm{S}}$ represent the ability of reduction and oxidation, respectively. For example, the redox potential of $\mathrm{O}_{2} / \mathrm{O}_{2}{ }^{--}$is $-0.33 \mathrm{~V}$ at $\mathrm{pH} 7$, and $\mathrm{SCP}_{\mathrm{S}}\left(\mathrm{E}_{\mathrm{C}}<-0.33 \mathrm{eV}\right)$ can bring electrons to $\mathrm{O}_{2}$, resulting in $\mathrm{O}_{2}{ }^{--}$formation. ${ }^{31}$ If hydrogen is extracted from water to

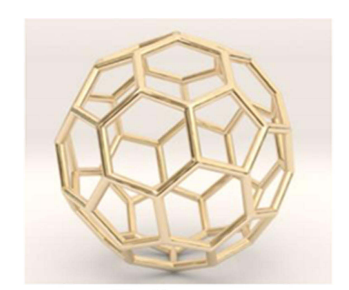

Fullerene

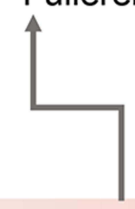

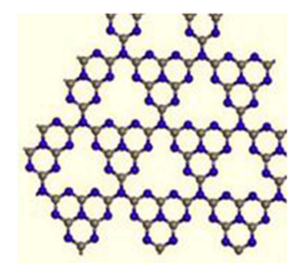

g- $\mathrm{C}_{3} \mathrm{~N}_{4}$

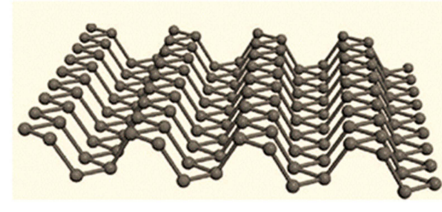

Black phosphorus

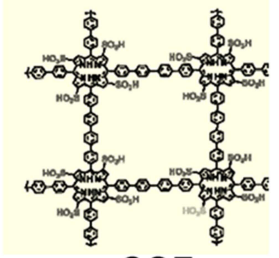

COF
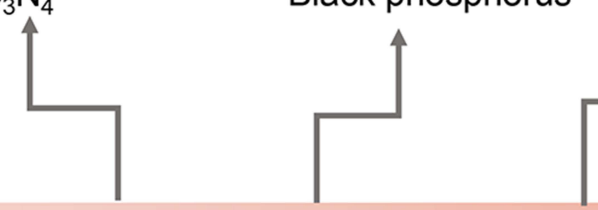

\section{$\begin{array}{lllllll}1997 & 2011 & 2012 & 2014 & 2015 & 2016 & 2017\end{array}$}
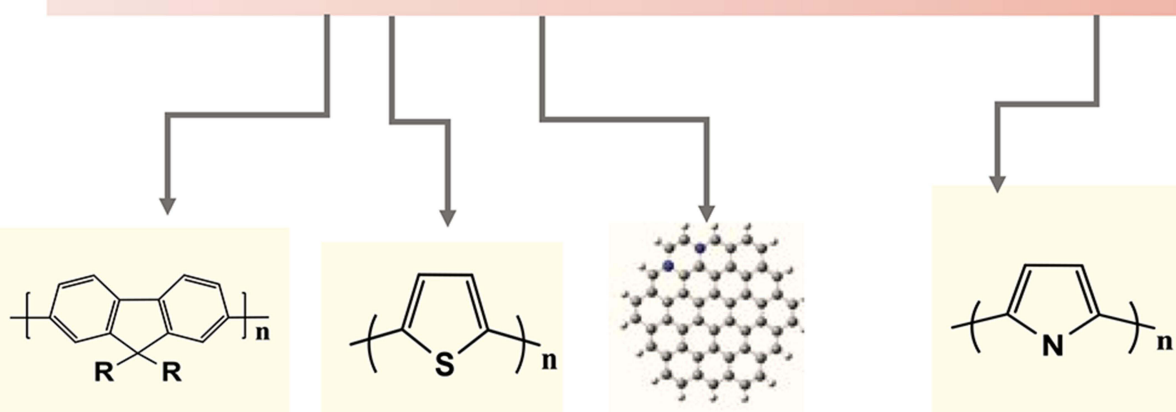

Polyfluorene

Polythiophene

Graphene quantum dots

Polypyrrole

Poly(cyclopentadithiophene -alt-benzothiadiazole)

Figure I Timeline of SCPs for PDT. 

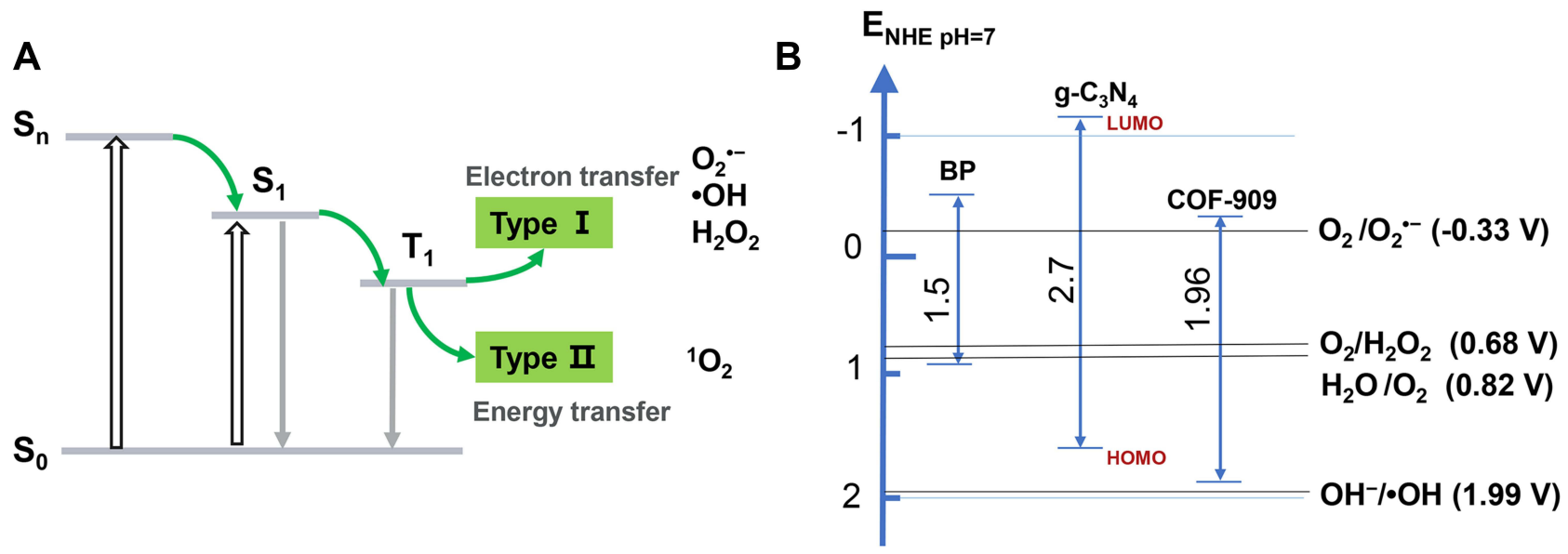

Figure 2 (A) Schematic illustration of SCPs photophysical and photochemical basis of PDT. (B) Reduction potential diagram of reactive oxygen species.

form hydroxyl radicals, $\mathrm{E}_{\mathrm{V}}>1.99 \mathrm{eV}$ are required because the redox potential of $\mathrm{H}_{2} \mathrm{O} / \bullet \mathrm{OH}$ at $\mathrm{pH} 7$ is $1.99 \mathrm{~V}^{31}$ If $\mathrm{Ev}$ is $>0.82 \mathrm{eV}$ and the redox potential of $\mathrm{H}_{2} \mathrm{O} / \mathrm{O}_{2}$ is $0.82 \mathrm{~V}$ at $\mathrm{pH} 7,{ }^{32} \mathrm{O}_{2}$ will be generated, which makes up for the lack of hypoxia in the tumor microenvironment. The bandgap of SCPs is $0.85-2.90 \mathrm{eV}$ (Table 1$),{ }^{33-44}$ when changing the type and content of monomers. To drive both $\mathrm{O}_{2}{ }^{--}$and - $\mathrm{OH}$ generation, the bandgap of $\mathrm{SCP}_{\mathrm{S}}$ is at least equal to the electrochemical potential $(\sim 2.22 \mathrm{eV})$. However, its tissue penetrability is only a few hundred microns. Reducing the bandgap can redshift the absorption edge and increase the light absorption in NIR to improve the

Table I Bandgap of SCPs

\begin{tabular}{|l|l|c|}
\hline SCPs & $\begin{array}{l}\text { Bandgap } \\
(\mathbf{e V})\end{array}$ & Reference \\
\hline Polyaniline & 2.90 & {$[33]$} \\
Polythiophene & 2.10 & {$[34]$} \\
Ladder-type polythiophene & $1.50-1.60$ & {$[34]$} \\
Polystyrene pyridine copolymer & $2.00-2.55$ & {$[35]$} \\
Polystyrene Pyridine thiophene & $1.95-2.31$ & {$[35]$} \\
terpolymer & & \\
Fluorene-based copolymers & $1.95-2.00$ & {$[36]$} \\
Poly(4,7-dithien-2-yl- & 1.10 & {$[37]$} \\
2,I,3-benzothiadiazole) & & \\
Polypyridine & 2.06 & {$[38]$} \\
Polypyrrole & $2.33-2.39$ & {$[39]$} \\
Polyacetylene & 1.35 & {$[40]$} \\
Fullerene & $0.85-1.24$ & {$[41]$} \\
Black phosphorus & $0.30-2.00$ & {$[42]$} \\
g-C ${ }_{3} N_{4}$ & 2.70 & {$[43]$} \\
Porphyrin-based COF & 1.60 & {$[44]$} \\
\hline
\end{tabular}

Abbreviations: COF, covalent organic framework; SCP, semiconducting conjugated polymers. tissue penetration. However, narrow bandgap means that $\mathrm{O}_{2}{ }^{--}$and $\cdot \mathrm{OH}$ cannot be obtained simultaneously. Therefore, for type I PDT, many researchers only satisfy one type of $\mathrm{O}_{2}{ }^{--}, \cdot \mathrm{OH}$, or enhance the type II PDT process to increase the yield of ${ }^{1} \mathrm{O}_{2}$. Type II PDT is energy transfer from PSs at $\mathrm{T}_{1}$ to triplet oxygen $\left({ }^{3} \mathrm{O}_{2}\right)$, resulting in cytotoxic singlet oxygen ${ }^{1} \mathrm{O}_{2} \cdot{ }^{45}$ The energy band between ${ }^{1} \mathrm{O}_{2}$ and ${ }^{3} \mathrm{O}_{2}$ is approximately $0.96 \mathrm{eV}$, indicating that type II PDT could use longer wavelength light. ${ }^{1}$ The activity of ROS is $\cdot \mathrm{OH}>^{1} \mathrm{O}_{2}$, which can cause extensive destruction of DNA chains, proteins, and cell membranes, ${ }^{46}$ while ${ }^{1} \mathrm{O}_{2}$ has higher reactivity to electron-rich acceptors of $\mathrm{C}=\mathrm{C}$, indole, and aromatic heterocycles. ${ }^{47}$

This review summarizes the latest strategies of $\mathrm{SCP}_{\mathrm{S}}$, which can overcome the tumor-associated barriers for significantly enhanced efficiency of PDT. First, we highlight the techniques to improve PDT effect of linear $\mathrm{SCP}_{\mathrm{S}}$ by improving solubility, adjusting conjugated structure, enhancing PS-doped SCPs, and combining therapies. Next, planar and three-dimensional (3D) SCPs are outlined briefly. Meanwhile, the current issues, such as hypoxia, low penetration, targeting and biosafety of $\mathrm{SCP}_{\mathrm{S}}$, and corresponding strategies, are summarized. Furthermore, the challenges and prospects for SCPs are also discussed. We hope this review sheds light on the development of PDT to accelerate the clinical translation of $\mathrm{SCP}_{\mathrm{S}}$.

\section{Linear SCPs}

Linear SCP is mainly composed of $\pi$-conjugated main chains and has unique conductive and photophysical properties due to its extended conjugation and configurable side chain, such as large absorption cross- 
section, excellent fluorescence brightness, excellent photostability and high emission rate, and low toxicity. Linear SCPs, including polythiophene, polyfluorene, and polyphenylene vinylene, have attracted considerable interest of researchers. However, due to the relatively low photosensitive efficiency of these polymers, some methods, such as improving the solubility of linear polymers, adjusting the conjugated structure of polymers, extending the length of conjugated main chain, designing D-A structure, enhancing PS-doped linear SCPs, and combining therapies, are discussed for enhanced PDT.

\section{Improving Water Solubility of Linear SCPs}

Water-soluble SCPs can be obtained by introducing cationic anions or other polar groups, which has excellent light capture ability and high fluorescence quantum yield. In 2011, Liu and Wang et al first explored the anticancer activity of polythiophene. ${ }^{25}$ Polythiophene P1 was used for PDT (Figure 3). ${ }^{12}$ However, polythiophene is a hydrophobic SCP with poor water solubility and poor biocompatibility in Schanze et al introduced cation imidazole $\mathrm{P} 2$ to improve water solubility and broaden the visible light absorption. ${ }^{48}$ Gary Bobo prepared amphiphilic cationic phosphine-based polythiophene P3. ${ }^{49}$ Moreover, Zhang prepared water-soluble $\mathrm{P} 4$ with high ${ }^{1} \mathrm{O}_{2}$ quantum yield (42\%), photostability and pH stability. ${ }^{50}$ Based on P4, Zhang shortened the hydrophobic carbon chain and prepared pure water-soluble P5 for enhanced PDT. ${ }^{10} \mathrm{Liu}$ synthesized a cationic water-soluble P6 with a quantum yield of $78 \%{ }^{51} \mathrm{P} 6$ entered the cells by hydrophobic interaction and by $\pi-\pi$ stacking and formed loose aggregates. Then, sulfhydryl groups are oxidized by high $\mathrm{H}_{2} \mathrm{O}_{2}$ levels in cancer cells to form disulfide bonds. Moreover, Ge et al prepared highly water-dispersible P7/(DSPE-PEG 2000), which generates more ${ }^{1} \mathrm{O}_{2}$ under the irradiation of $532 \mathrm{~nm}$ laser. ${ }^{11}$ Xing prepared P8/polyisocyanide (PIC) hybrid hydrogel. PIC hydrogel has fiber structure and nonlinear mechanical properties and can be used as template for P8. It has higher ROS generation than P8 under red light and has good thermal reversibility and biocompatibility. ${ }^{17}$ Therefore, introducing charged or sulfhydryl groups into the side chain of linear SCPs and combining with solubilizers can effectively enhance water solubility and biocompatibility to extend retention time in vivo and enhance PDT.

\section{Adjusting Conjugated Structure of Linear SCPs}

The common method to enhance the efficiency of PSs is to improve the ISC from the lowest excited state $\left(\mathrm{S}_{1}\right)$ to the lowest triplet state $\left(\mathrm{T}_{1}\right)$.

According to the perturbation theory, the rate constant $\left(k_{\mathrm{ISC}}\right)$ of ISC is given by the following formula: ${ }^{52}$

$k_{I S C} \propto\left\langle{ }^{1} \Psi\left|\hat{H}_{S O}\right|^{3} \Psi\right\rangle / \exp \left(\Delta E_{S T}^{2}\right)$

where $\left\langle{ }^{1} \Psi\left|\hat{H}_{S O}\right|^{3} \Psi\right\rangle$ is the spin-orbit coupling (SOC) matrix element, $\hat{H}_{S O}$ is the SOC Hamiltonian, and $\Delta E_{S T}$ is the energy gap between the singlet and triplet states. According to the formula, increasing SOC matrix element can increase the $k_{\text {ISC }}$ value. Extending SCP conjugate length ${ }^{53}$ or adding heavy atoms, such as iodine, ${ }^{54}$ bromide, and seleniumplatinum, ${ }^{55}$ into organic p-conjugated system can improve

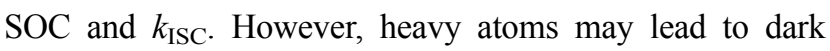
toxicity in biological applications. Another method is to reduce $\Delta E_{S T}$ by designing the conjugated structure of donor (D) and acceptor (A) units. ${ }^{56}$ Therefore, we will discuss the following methods of improving the efficiency of $\mathrm{SCP}_{\mathrm{S}}$ to generate more ROS for PDT.

First, extending the length of conjugated main chain improve the ISC. Bazan designed oligomers and P9 with DTPEAQ as repeating unit. The ${ }^{1} \mathrm{O}_{2}$ quantum yield of P9 is $82 \%$ and that of the oligomer DTPEAQ is only $38 \%{ }^{3}$ Similarly, Liu synthesized two SCPs P10 and P11, based on the small-molecule TPEDC. ${ }^{57}$ The singlet and triplet energy levels of SCPs are usually much denser than those of their small-molecule analogs, which is beneficial to ${ }^{1} \mathrm{O}_{2}$ generation in the ISC process (Figure 4).

Based on SCPs, the conjugated length is further extended. $\mathrm{Xu}$ and Tan et al added a phenylene acetylene group to polythiophene main chain (P12), ${ }^{13}$ which is helpful in enhancing the light trapping of polymer main chain to ensure strong fluorescence and photosensitivity. P12 can effectively generate ${ }^{1} \mathrm{O}_{2}$ under white light, destroy lysosomal membrane and lysosomal enzyme in the cytoplasm, and promote cell death. Moreover, by introducing ethynyl and vinyl as the bridge, Xu synthesized three water-soluble P13-15. The two-photon absorption cross-section at 800 $\mathrm{nm}$ of P15 (ethylene bridge) was 4.5 times that of P14 (acetylene bridge) and 36 times that of P13. ${ }^{27}$ Larger twophoton absorption cross-section can effectively absorb longer wavelengths and treat diseased tissues more deeply.

Second, designing the conjugated structure of donor (D) and acceptor (A) units could reduce $\Delta E_{S T}$. Combination of $\mathrm{D}$ and $\mathrm{A}$ into a molecule could produce 

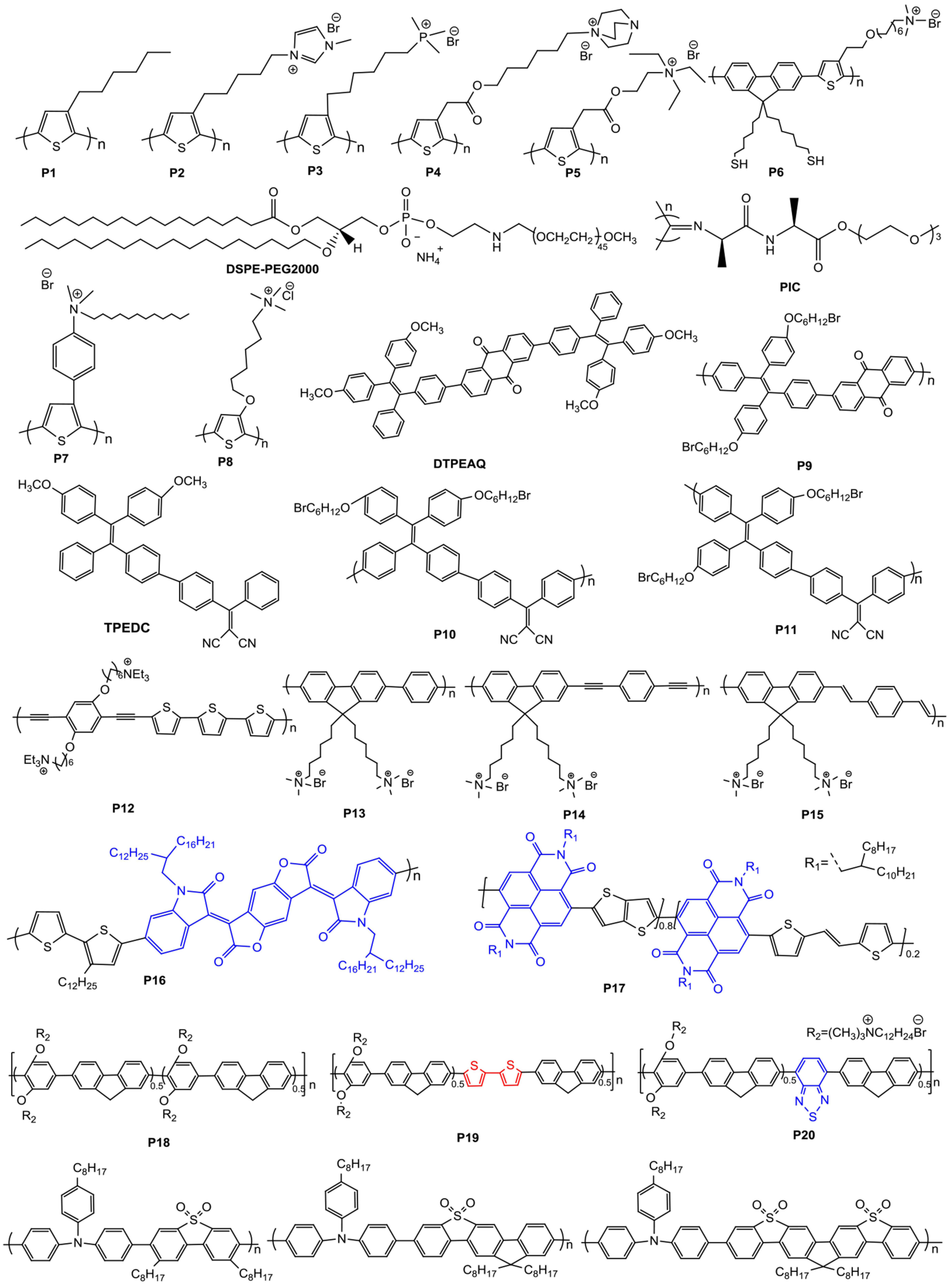

P21

P19

P20

$\mathrm{R}_{1}=: \underbrace{\mathrm{C}_{8} \mathrm{H}_{17}}_{\mathrm{C}_{10} \mathrm{H}_{21}}$

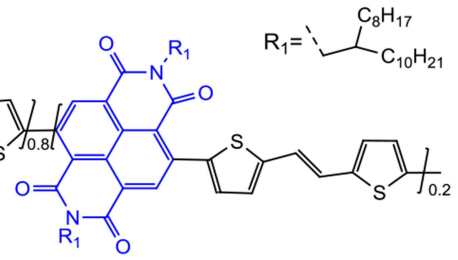



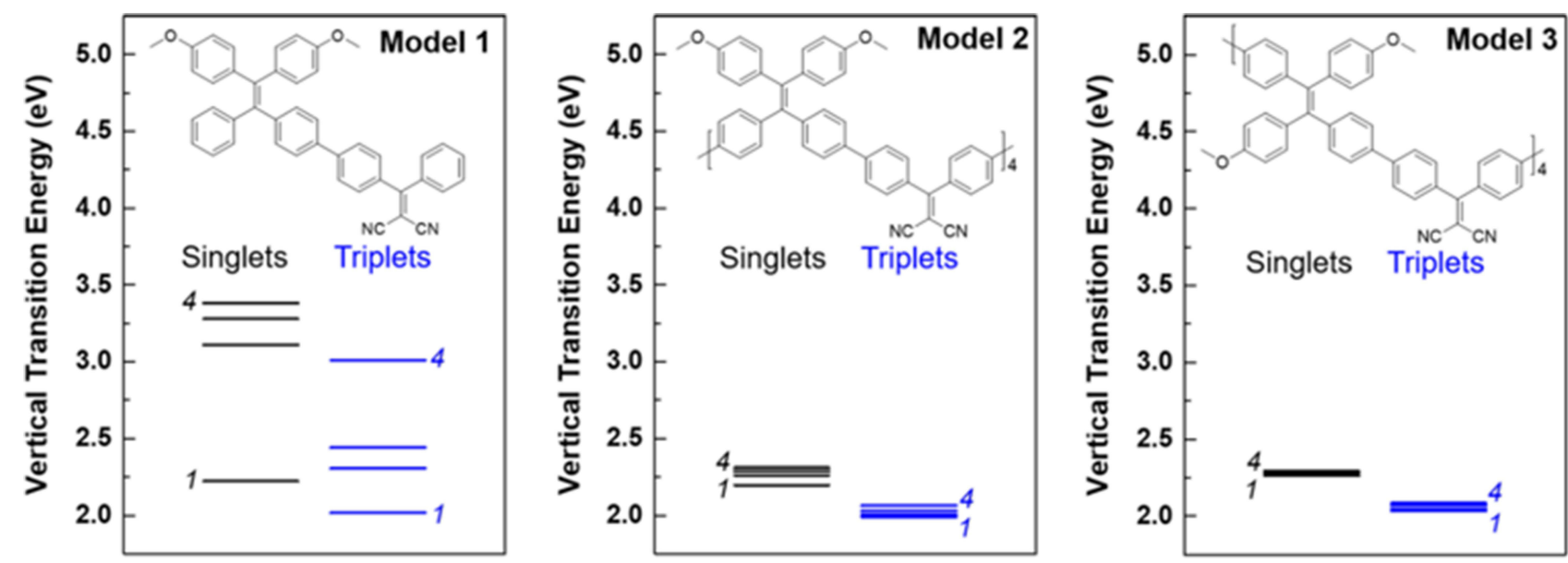

Figure 4 Chemical structures and singlet and triplet energy levels of three model compounds.

Notes: Reproduced with permission from: Wang S, Wu W, Manghnani P, et al. Polymerization-enhanced two-photon photosensitization for precise photodynamic therapy. ACS Nano. 2019;13(3):3095-3105. ${ }^{57}$ Copyright @ 2019, American Chemical Society.

new hybridized molecular orbitals with higher HOMO level and lower LUMO level to render a small bandgap with long wavelength absorption. ${ }^{58}$ Ge introduced isoindigo derivatives into the main chain of polythiophene and prepared small bandgap D-A SCPs P16. It has a significant NIR absorption peak at $782 \mathrm{~nm}$ and an obvious ${ }^{1} \mathrm{O}_{2}$ quantum yield under NIR. ${ }^{59}$ Yang synthesized a threecomponent $\mathrm{P} 17$ with low dark toxicity and high ${ }^{1} \mathrm{O}_{2}$ quantum yield of $42.2 \%$ in dichloromethane solvent. ${ }^{60}$ Based on "fluorene-phenylene" structural unit P18, Wang designed electron-rich thiophene P19 and electrondeficient benzothiadiazole P20 to improve optical properties. Adding electron-deficient groups to the fluorenephenylene structure can significantly improve ROS generation. ${ }^{61}$ Guo et al ${ }^{62}$ synthesized P21-23 containing dibenzothiophene-S and S-dioxide derivative acceptors and introduced SO units into conjugated main chains, which had a narrower bandgap, thus enhancing the electron transport capacity. ${ }^{63} \mathrm{P} 22$ has a relatively large twophoton absorption cross-section of $3.29 \times 10^{6} \mathrm{GM}$ and good ROS generation capacity.

Tang et $\mathrm{al}^{64}$ prepared four types of SCPs P24-27 with electron donating (red) and withdrawing groups (blue) (Figure 5). The ROS generation rate of poly(fluorene cophenylene acetylene) derivatives P25, P26, and P27 is higher than that of poly(fluorene-phenylene) derivative $\mathrm{P} 24$, and the D- $\pi$-A structure is better than the A- $\pi-\mathrm{A}$ structure. Similarly, Tang et $\mathrm{al}^{65}$ designed three SCPs P28-P30 with three small molecules, BTB, TCNT, and MAQM. The results showed that SCPs have higher ROS generation efficiency than small molecules. They also designed D-A-D and A-D-A (L1vsL2, L3vsL4, L5vsL6, blue as receptor unit). The A-D-A structure has higher photosensitive efficiency than the D-A-D structure (L1 < L2, L3 < L4, L5 < L6).

The abovementioned results show that introducing electron-withdrawing groups into the linear conjugated main chain can effectively improve ROS generation, and its performance is affected by the proportion and arrangement order of D-A units; for example, D- $\pi$-A is superior to A- $\pi-A$, and A-D-A is superior to D-A-D.

\section{PS-Doped Linear SCPs}

Fluorescence resonance energy transfer (FRET) effect refers to SCPs as donor and other photosensitizers (porphyrin, isoindigo derivatives) as acceptor and excitation energy transfer from SCPs to PSs leading to ROS generation. In 2011, Liu and Wang et al reported a water-soluble P31 (Figure 6), polythiophene-containing porphyrin in the side chain. ${ }^{25}$ The excitation energy transfer from polythiophene main chain to porphyrin improved ROS generation. Compared with porphyrin, the survival rate of cancer cells is significantly reduced under $470 \mathrm{~nm}$ irradiation. Yang et $\mathrm{al}^{50}$ synthesized P33 and P34 with tamoxifen and porphyrin receptors, respectively. The MCF-7 cells viability of P33 only decreased to $60 \%$, while that of P32 decreased to $40 \%$. The abovementioned two studies show that the short energy transfer distance of side chain porphyrin improved the ROS generation efficiency. SCPs can also be a chemical energy receptor. Liu et al ${ }^{66}$ designed P35 as donor and tetraphenyl-porphyrin as acceptor. Meanwhile, P35 is also a chemical energy receptor from $\mathrm{H}_{2} \mathrm{O}_{2}$ 


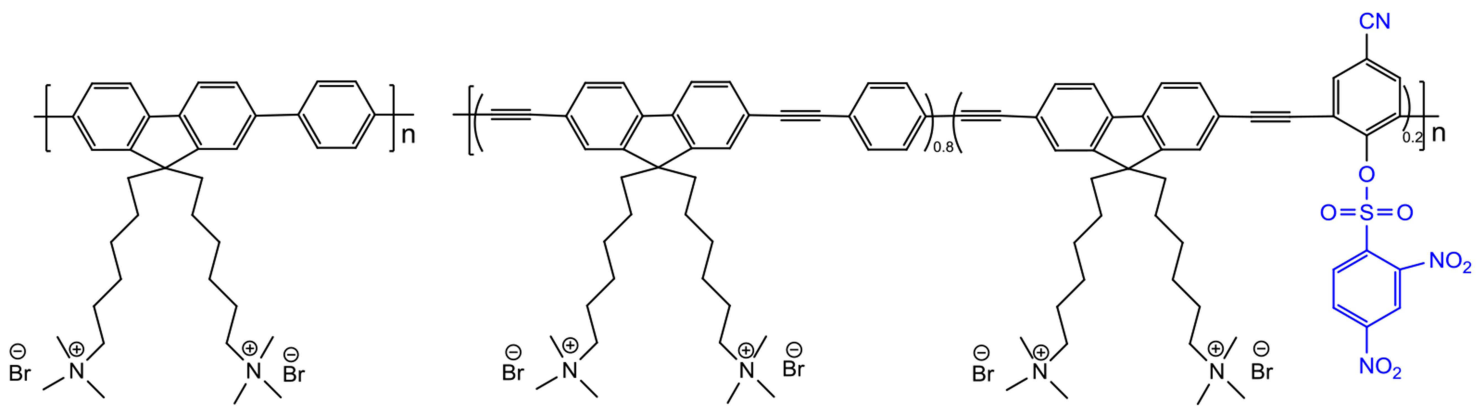

P24

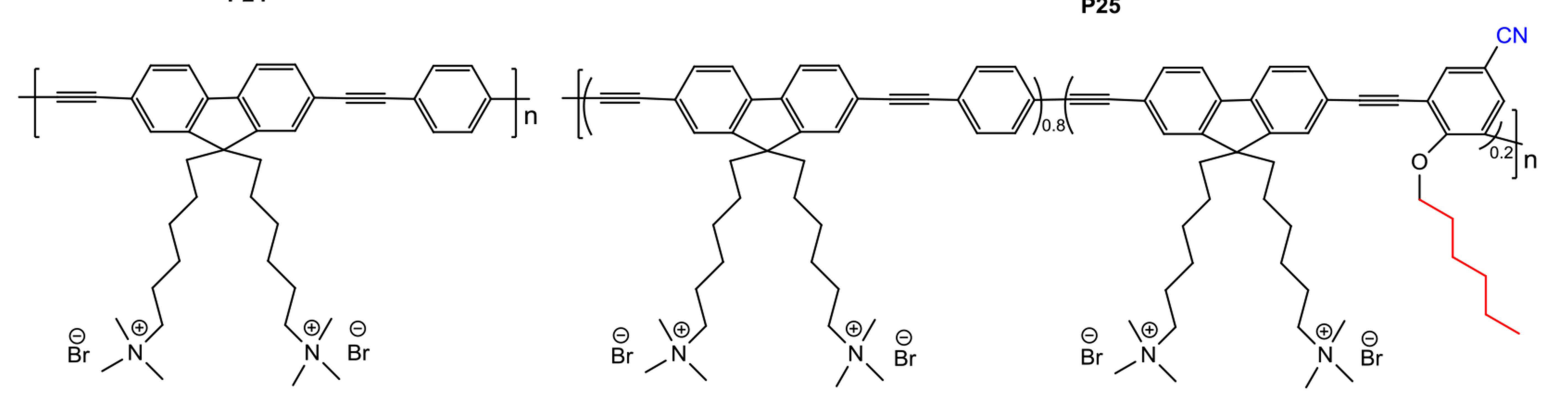

P27
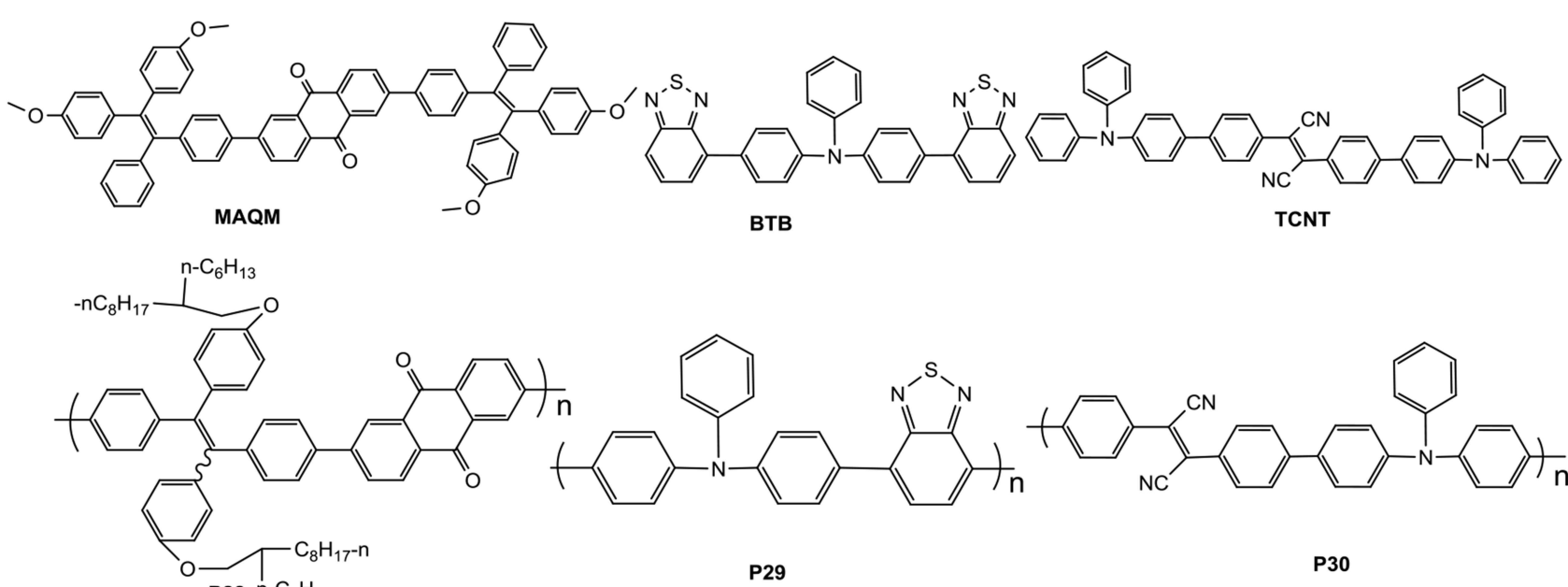

P28 $\mathrm{n}-\mathrm{C}_{6} \mathrm{H}_{13}$
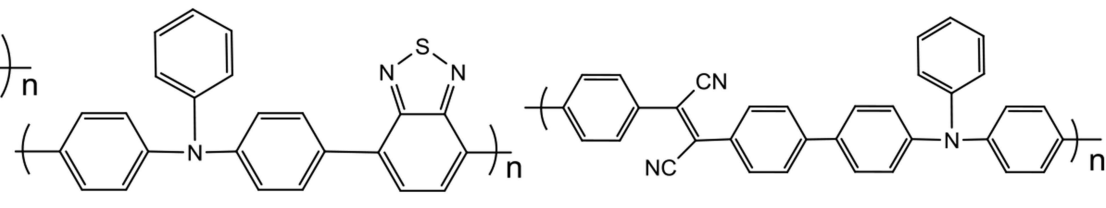

P29

P30

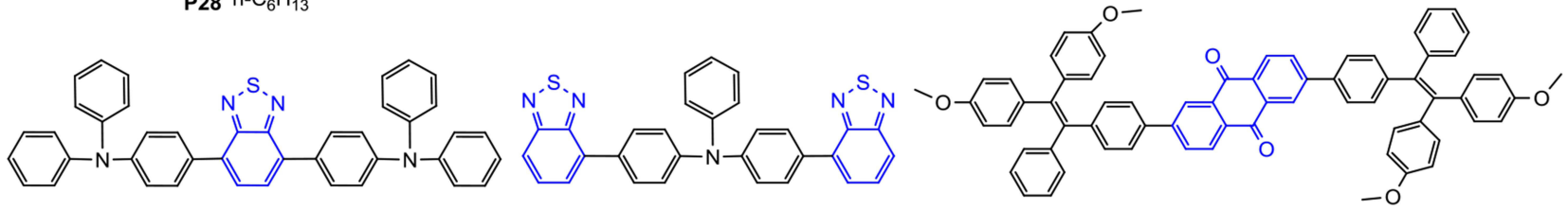

L1

L2

L3

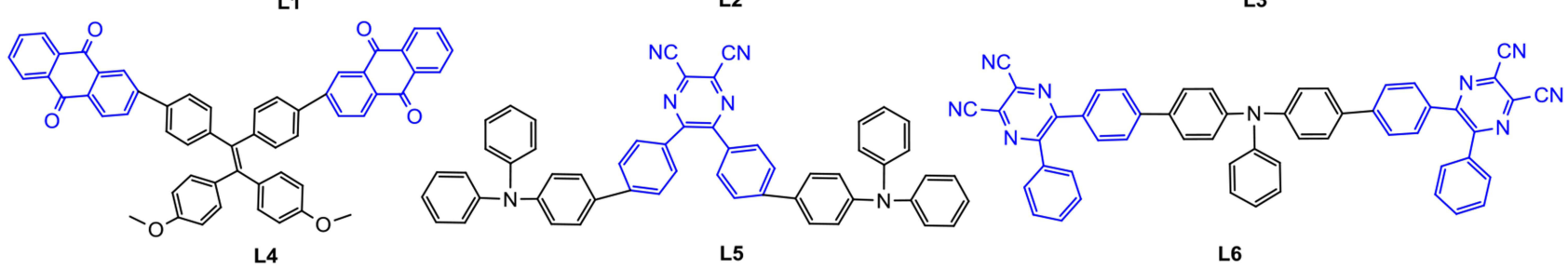

Figure 5 Chemical structures of SCPs (electron acceptors are shown in blue; electron donors are shown in red). 

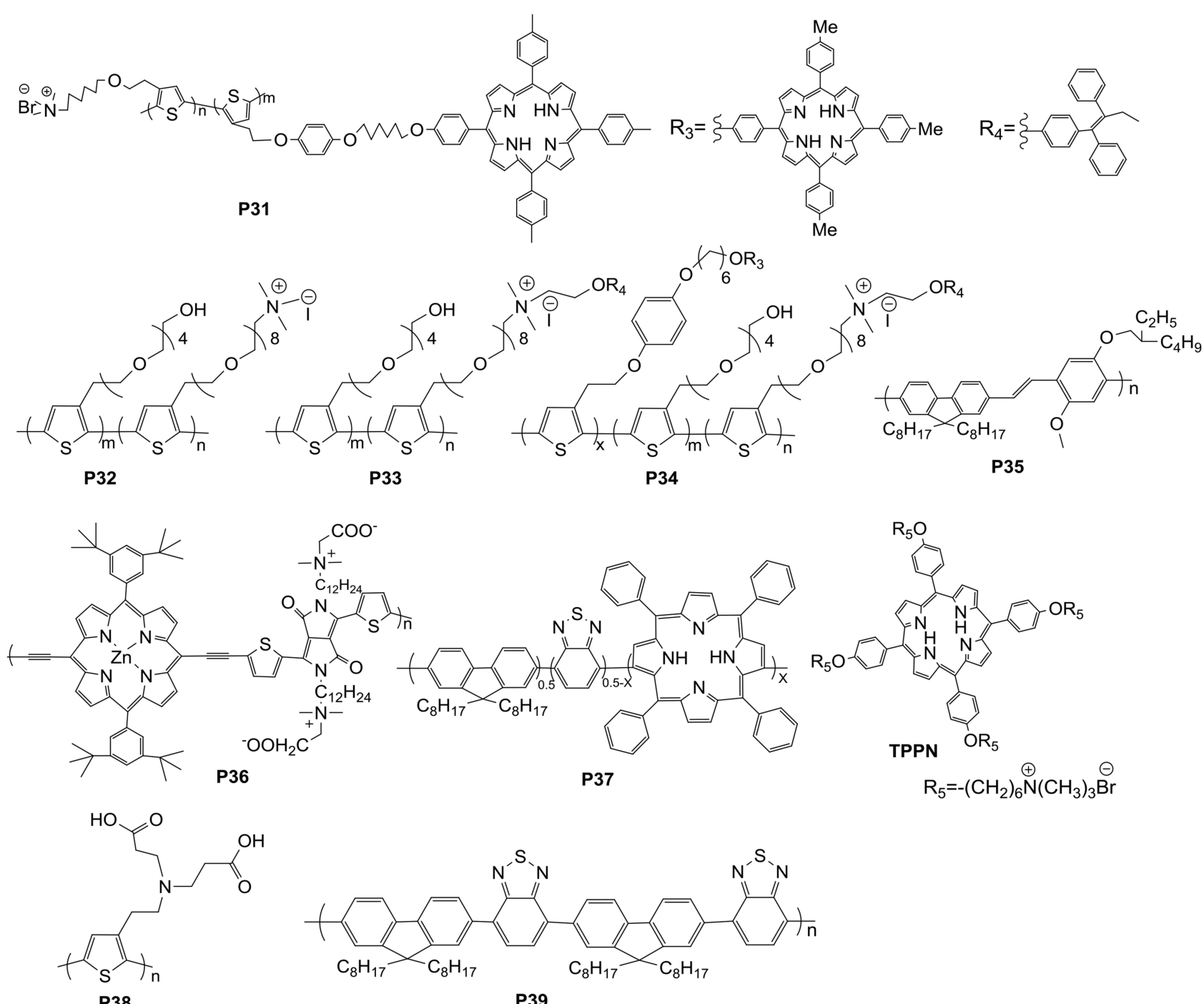

P38

P39

Figure 6 Chemical structures of SCPs for PDT.

reaction. This energy transfer strategy has strong NIR chemical luminescence and good ${ }^{1} \mathrm{O}_{2}$ generation capability.

Moreover, Zhang et $\mathrm{al}^{67}$ added porphyrin into conjugated main chain (P36). It has the best absorbance at 700$850 \mathrm{~nm}$ and can generate ROS without $\mathrm{pH}$ effect. Wu et $\mathrm{al}^{68}$ also introduced tetraphenyl-porphyrin into the main chain of P37, which not only achieved high quantum yield of ${ }^{1} \mathrm{O}_{2}$ generation (35\%) but also solved issues of PS leaching and low dark toxicity, effectively damaging cancer cells and inhibiting xenograft tumor. Without covalently linking porphyrins to SCPs side or main chains, Wang et al synthesized anionic water-soluble P38 and cationic porphyrin (TPPN) complexes by electrostatic interaction between anionic SCPs and cationic porphyrins. $^{69}$ P38 and TPPN have an effective energy transfer. Moreover, TPPN's energy is transferred to the triplet state by ISC; then, ${ }^{3} \mathrm{O}_{2}$ is sensitized to improve ${ }^{1}$ $\mathrm{O}_{2}$ generation efficiency and enhance PDT. Hydrophobic tetraphenyl-porphyrin and P39 were prepared to dense semiconductor polymer points by reprecipitation. ${ }^{70}$ The energy transfer efficiency is close to $100 \%$, resulting in approximately $50 \%{ }^{1} \mathrm{O}_{2}$ quantum yield.

\section{Hyperbranched SCPs}

In addition to the traditional linear main chain structure, branched SCPs is also worth exploring. Adams and Cooper et $\mathrm{al}^{71}$ prepared a series of amorphous microporous organic polymer P40 with specific surface area of $1710 \mathrm{~m}^{2} \mathrm{~g}^{-1}$ and adjusted the bandgap in the range of $1.94-2.95 \mathrm{eV}$ (Figure 7). The authors only found that this polymer had good performance of photocatalytic hydrogen evolution. 

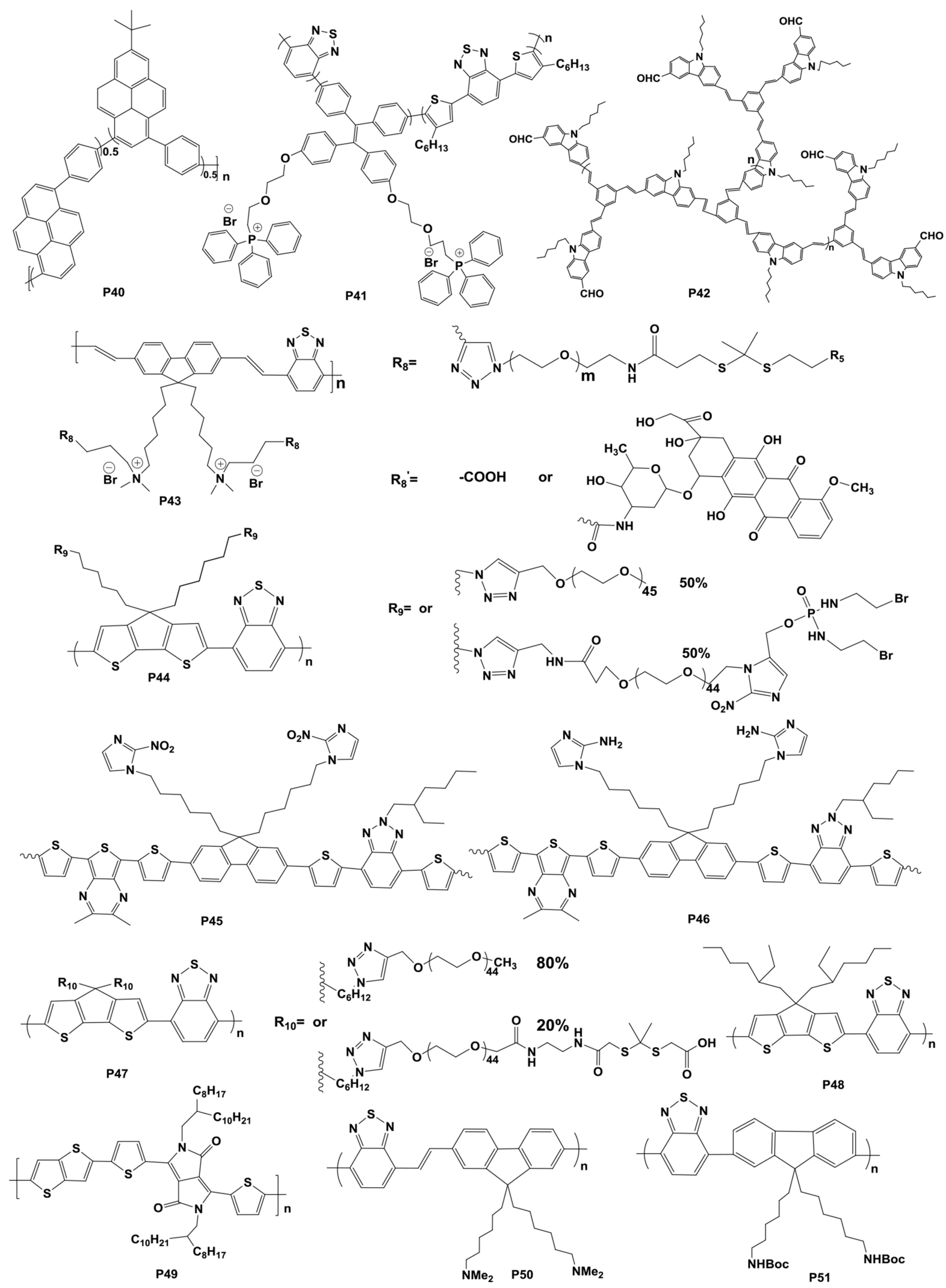

Figure 7 Chemical structures of SCPs. 
The polymer with $1.94 \mathrm{eV}$ bandgap can be used for PDT, but the PDT efficiency needs to be further studied. Zhou et $\mathrm{al}^{72}$ reported polymer P41 with aggregation-induced emission (AIE) characteristics, red emission peak at 638 $649 \mathrm{~nm}$, and 25.0-30.6\% fluorescence quantum yield in the aggregated state. It is suitable for PDT as a PS. Huang et $\mathrm{al}^{73}$ designed a hyperbranched polymer $\mathrm{P} 42$. The $\mathrm{QY}$ in water is $27 \%$ at $800 \mathrm{~nm}$. He also prepared P42/hyperbranched polyether (photothermal agent) $/ \mathrm{Ce}_{6}$ for twophoton excited PDT. The phase transition from the extended coil to the folded sphere shortens the distance between P42 and $\mathrm{Ce}_{6}$, which is conducive to ${ }^{1} \mathrm{O}_{2}$ generation by FRET.

\section{Combined Therapies and Regulation of Drug Release by Microenvironment}

With a small radius of action $(<20 \mathrm{~nm})$ and short lifespan ( $<40 \mathrm{~ns}$ ) for ${ }^{1} \mathrm{O}_{2},{ }^{74}$ one strategy for overcoming these limitations is combining with other therapies. To achieve the combination of PDT and chemotherapy, PSs and chemotherapeutic drugs need to be used in a drug delivery system to regulate drug release through ROS concentration, $\mathrm{pH}$, and temperature in the tumor microenvironment. Liu et $\mathrm{al}^{75}$ regulated the release of chemotherapeutic drugs by ROS. They combined P43 with doxorubicin (DOX) by a ROS-cleavable thioketal linker. P43 generates ROS under light, which can not only kill cells but also cut the linker at a specific location to release DOX. The results showed that the combination therapy has a stronger inhibitory effect on cell viability than single therapy. Furthermore, the release of chemotherapeutic drugs can be activated by hypoxia. Pu et $\mathrm{al}^{76}$ synthesized a nanodrug system, amphiphilic P44 linked with PEG and chemotherapeutic drug isophosphatin mustard intermediate (IPM-Br) (Figure 8A). Catalyzed by nitro reductase, the hypoxia specifically initiated the cleavage and release of IPM-Br, leading to cell death. Its PDT efficiency is 18 times higher than that of the control group. Moreover, the antitumor effect is 4.3 times higher than that of P44 under NIR and hypoxia. Therefore, the combination of PDT and hypoxia-activated chemotherapy can be used in collaborative amplification of cancer therapy. Shen et $\mathrm{al}^{77}$ designed a system for hypoxia activation and release of chemotherapeutic drugs. P45 was synthesized, in which dithiophenylbenzotriazole was used in ROS generation, dithiophenylpyrazine as NIR imaging agent, and 2-nitroimidazole as side chain hydrophobic component for hypoxia response transduction. The DOX was encapsulated by double emulsion solvent evaporation/ extraction and coated with polyethylene alcohol. In hypoxia, the side chain can be transformed into hydrophilic 2-aminoimidazole P46 through the single electron reduction of a series of nitroreductases and biological reducing agents (eg, abundant coenzymes in tissues), promoting the degradation of DOX/SCP nanoparticles. This SCP release system can effectively generate ROS and induce hypoxia to promote its release in cells for combined therapy.

In addition to combined chemotherapy, $\mathrm{Pu}$ et $\mathrm{al}^{78}$ designed $\mathrm{P} 47$ to induce photodynamic-immuno metabolic therapy by ${ }^{1} \mathrm{O}_{2}$. The ${ }^{1} \mathrm{O}_{2}$ generated from $\mathrm{P} 47$ can not only induce PDT but also stimulate the release of tumorassociated antigen and activate kinase, leading to loss of Kyn and increase in the proliferation and infiltration of effector $\mathrm{T}$ cells, improving the whole-body anticancer immunity. The researchers adjusted the ROS level according to $\mathrm{pH}$ conditions. Zhu and Fang et $\mathrm{al}^{79}$ revealed a compound with $\mathrm{P} 48$ and $\mathrm{CeO}_{2}$, which can change the ROS level according to the changing microenvironment and reduce the damage to the surrounding normal tissue (Figure 8B). As a photosensitizer, P48 has strong absorption in NIR, and nanoceria can be an ROS scavenger and converter according to $\mathrm{pH}$ and generate less radicals under neutral condition to distinguish normal tissue and tumor and improve the therapeutic selectivity.

PDT depends on ROS but is limited by the oxygen level of the tumor microenvironment. PTT depends on the photothermal conversion of nonradioactive decay, regardless of the oxygen supply. The combination of PDT and PTT can compensate each other to improve phototherapy. For example, Yuan prepared P49. ${ }^{80}$ Its temperature rose rapidly to $69.5^{\circ} \mathrm{C}$ in $5 \mathrm{~min}$ to severe photothermal cell damage under $808 \mathrm{~nm}$ laser irradiation. Recently, amphiphilic P3 was found to assemble with siRNA effectively, deliver siRNA targeting luciferase gene in MDA-MB-231 cancer cells expressing luciferase, and lead to $35 \%$ and $52 \%$ gene silencing effect. Meanwhile, the photodynamic activity of $\mathrm{P} 3$ was restored after siRNA delivery, proving their potential in the combination of PDT and gene therapy. ${ }^{49}$

Thus, improving the solubility by side chain modification could prolong the duration of efficacy in vivo. Adjusting the molecular composition of polymer could improve the electron and energy transfer in PDT and promote ROS generation. Combination with other 

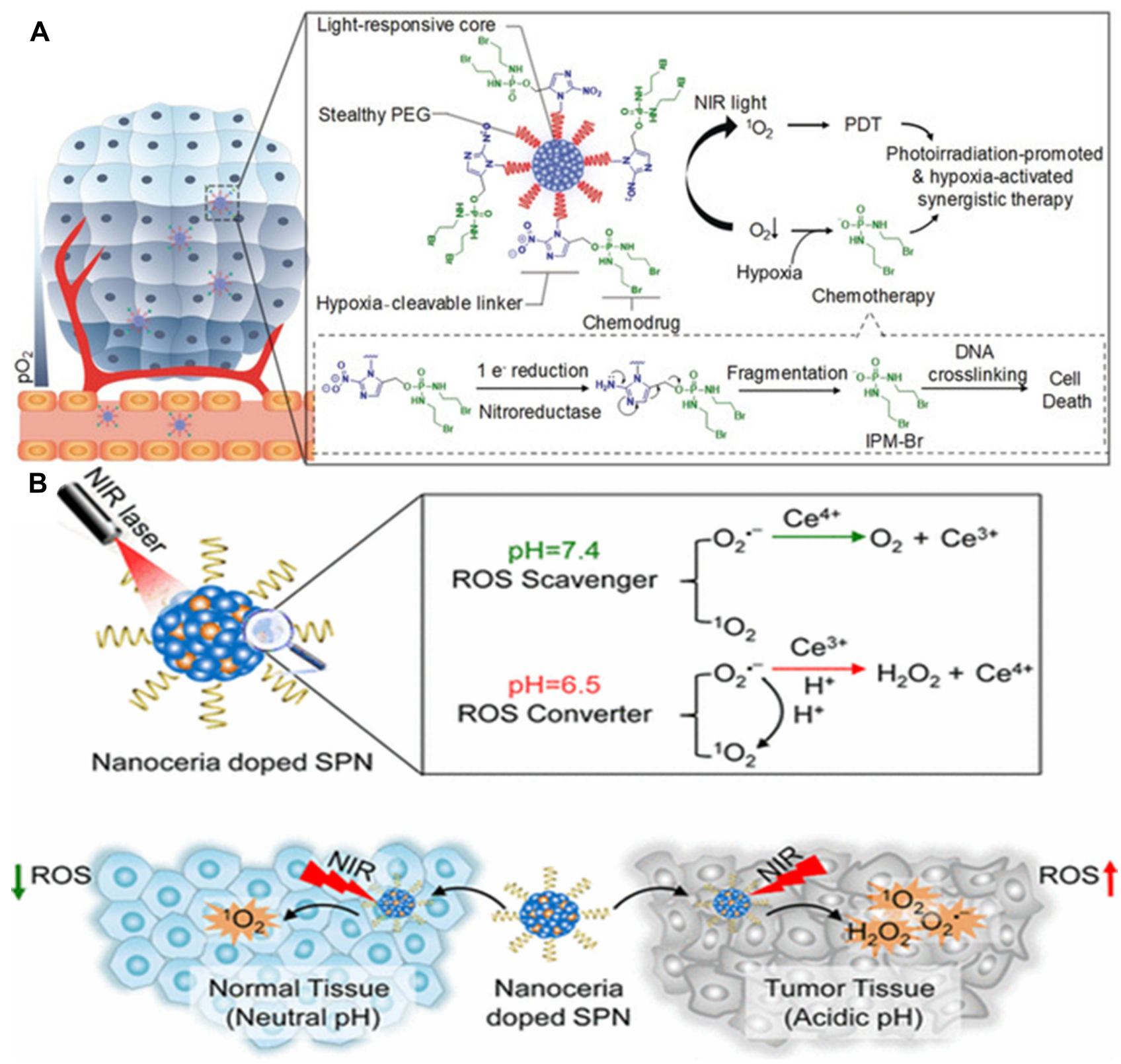

Figure 8 (A) Schematic illustration of P44 for hypoxia-activated synergistic PDT and chemotherapy. Reproduced from: Cui D, Huang J, Zhen X, Li J, Jiang Y, Pu K. A semiconducting polymer nano-prodrug for hypoxia-activated photodynamic cancer therapy. Angew Chem Int. 2019;58(I8):5920-5924. ${ }^{76} \mathrm{Copyright} @ 2019 \mathrm{Wiley-VCH}$ Verlag GmbH \& Co. KGaA, Weinheim. (B) Schematic illustration of the self-regulated photodynamic properties of P48 at physiologically neutral, pathologically acid conditions and comparison between selfregulated and conventional. Reproduced with permission from: Zhu H, Fang Y, Miao Q, et al. Regulating near-infrared photodynamic properties of semiconducting polymer nanotheranostics for optimized cancer therapy. ACS Nano. 20I7; I (9):8998-9009..$^{79}$ Copyright (C) 20I7, American Chemical Society.

therapies improve hypoxia restriction. Therefore, the merits of SCP modification can be integrated to enhance PDT.

\section{Two-Dimensional (2D) SCPs}

Studies show that extending the SCP size from 1D to 2D can reduce the Coulomb binding energy so that the electron hole pairs can be dissociated, thus increasing exciton dissociation yield to generate ROS. Recently, popular 2D SCPs include $\mathrm{g}_{-} \mathrm{C}_{3} \mathrm{~N}_{4}$, black phosphorus (BP), and GQDs. Many researchers reviewed the drug delivery, imaging, and phototherapy of 2D SCPs. ${ }^{19,20,81,82}$ This review focuses on the modification of 2D SCPs for enhanced PDT.

\section{$g-\mathrm{C}_{3} \mathrm{~N}_{4}$}

Recently, g- $\mathrm{C}_{3} \mathrm{~N}_{4}$ has attracted widespread attention as PSs for PDT. It is a 2D layered SCP with inherent 
semiconductor characteristics, biocompatibility, and excellent chemical stability. ${ }^{81}$ The bandgap is $2.7 \mathrm{eV}$, and $\mathrm{O}_{2}{ }^{-}, \mathrm{O}_{2}$, and $\mathrm{O}_{2}$ can be generated under visible light. ${ }^{83}$ Presently, the PDT bottlenecks of $\mathrm{g}_{-} \mathrm{C}_{3} \mathrm{~N}_{4}$ are poor tissue penetration and hypoxia. To solve these issues, researchers adjust the optical properties of $\mathrm{g}_{-} \mathrm{C}_{3} \mathrm{~N}_{4}$ by developing $\mathrm{g}$ $\mathrm{C}_{3} \mathrm{~N}_{4}$ quantum dots (QDs), doping, and heterojunction, which allow redshift light absorption and increase NIR absorption. Then, combined with other PSs and upconversion materials, the utilization of light can be improved to maximum. Lastly, g- $\mathrm{C}_{3} \mathrm{~N}_{4}$ can be combined with chemotherapy and immunotherapy to improve the anticancer effect.

\section{Modification of $\mathrm{g}-\mathrm{C}_{3} \mathrm{~N}_{4}$ Inherent Structure}

First, regarding bulk size of $\mathrm{g}-\mathrm{C}_{3} \mathrm{~N}_{4}$ and poor solubility, researchers developed g- $\mathrm{C}_{3} \mathrm{~N}_{4}$ QDs, which has good biocompatibility and small size and is beneficial in cell ingestion. Wei ${ }^{84}$ prepared g- $\mathrm{C}_{3} \mathrm{~N}_{4}$ QDs ( $\left.\sim 30 \mathrm{~nm}\right)$ modified by nitrogenrich monomer with better ROS generation. Zhang ${ }^{85}$ reported low cytotoxicity and good biocompatibility of $\mathrm{g}-\mathrm{C}_{3} \mathrm{~N}_{4}$ QDs $(5 \mathrm{~nm})$ an excellent PS for microwave-induced PDT. Second, the bandgap of $\mathrm{g}_{-} \mathrm{C}_{3} \mathrm{~N}_{4}$ is $2.7 \mathrm{eV}$ and can be activated by green light, which causes low penetration depth and limits therapeutic effect to the deep tumor. Reducing bandgap by element doping could broaden NIR absorption to increase penetration depth. Xu et $\mathrm{al}^{86}$ prepared $1.95 \mathrm{eV}$ bandgap g$\mathrm{C}_{3} \mathrm{~N}_{5}$, corresponding to the absorption edge at $636 \mathrm{~nm}$. The activity of g- $\mathrm{C}_{3} \mathrm{~N}_{5}$ generated $\mathrm{O}_{2}$ and ${ }^{1} \mathrm{O}_{2}$ is approximately 9.5 times that of the original sample. Moreover, Cai et $\mathrm{al}^{87}$ doped g- $\mathrm{C}_{3} \mathrm{~N}_{4}$ with alkali metal $\mathrm{Zn}^{2+}$ and $\mathrm{K}^{+}$, its absorption edge was adjusted from $460 \mathrm{~nm}$ to $663 \mathrm{~nm}$, and the bandgap was reduced to $1.94 \mathrm{eV}$. The ROS release rate of doped g- $\mathrm{C}_{3} \mathrm{~N}_{4}$ was approximately $45.16 \%$ (the original sample was $7.95 \%$ ). Lastly, heterojunction can promote electron transfer and ROS generation. ${ }^{88} \mathrm{Lu}$ and Yang ${ }^{89}$ synthesized a g- $\mathrm{C}_{3} \mathrm{~N}_{4} @$ PDA heterojunction. The absorption range of PDA can be extended from ultraviolet (UV) to NIR $(660 \mathrm{~nm})$. Li and Yang reported 5-10 nm gold nanoparticle (AuNP) could absorb $670 \mathrm{~nm}$ light energy, and excited electrons were injected into g- $\mathrm{C}_{3} \mathrm{~N}_{4}$ nanofilms, which extended the process of photoinduced charge separation and delayed the combination of electron-hole pairs to enhance type I PDT. ${ }^{90,91}$

\section{PS-Doped g- $\mathrm{C}_{3} \mathrm{~N}_{4}$ for PDT}

PSs has a strong ability to generate ROS, but it is limited by oxygen concentration. g- $\mathrm{C}_{3} \mathrm{~N}_{4}$ can generate oxygen by water splitting. Conversely, the energy transfer of PSs and $g-\mathrm{C}_{3} \mathrm{~N}_{4}$ can enhance PDT. Chen et $\mathrm{al}^{92}$ synthesized a water-soluble, $\mathrm{pH}$-activated $\mathrm{g}-\mathrm{C}_{3} \mathrm{~N}_{4}$ nanomaterial with coupled porphyrin. ${ }^{1} \mathrm{O}_{2}$ was generated by FRET between $\mathrm{g}-\mathrm{C}_{3} \mathrm{~N}_{4}$ and porphyrin, which was highly toxic, especially in the more acidic environment of cancer cells. Similarly, Cai et al ${ }^{93}$ combined g$\mathrm{C}_{3} \mathrm{~N}_{4}$ with TMPyP4-porphyrin, which has good stability in physiological solution and selective aggregation in tumor cells. Under hypoxia, it can effectively inhibit A431 human epidermoid cancer cell growth. Cheng et $\mathrm{al}^{94}$ prepared iron-doped carbon nitride $\left(\mathrm{Fe}-\mathrm{C}_{3} \mathrm{~N}_{4}\right) / \mathrm{Ru}(\mathrm{II})$ complex/ hyperbranched SCP with poly(ethylene glycol). Poly(ethylene glycol) is a high two-photon collector and FRET's donor. $\mathrm{O}_{2}$ was released to compensate for oxygen consumption during PDT and promote ${ }^{1} \mathrm{O}_{2}$ generation under $800 \mathrm{~nm}$ two-photon radiation. The multiple PSs show more effective separation of electron hole pairs and significantly higher light utilization efficiency and enhanced PDT efficiency than any single PS.

\section{Combined Therapy}

$\mathrm{g}_{-} \mathrm{C}_{3} \mathrm{~N}_{4}$ is an effective chemotherapeutic drug carrier for enhancing the anticancer effect because of its high specific surface area. For the first time, $\mathrm{Li}$ et $\mathrm{al}^{95}$ showed that $\mathrm{g}-\mathrm{C}_{3} \mathrm{~N}_{4}$ nanosheets to be used as a carrier of $\mathrm{pH}$ responsive nanodrug DOX. Chen et $\mathrm{al}^{96}$ prepared g$\mathrm{C}_{3} \mathrm{~N}_{4}$ as core and ZIF-8 with DOX as shell. Wang et al ${ }^{97}$ also used melamine and phloxine $\mathrm{B}$ precursor polymerization to synthesize black $\mathrm{g}-\mathrm{C}_{3} \mathrm{~N}_{4}$ with PDT and PTT effects. Black $\mathrm{g}-\mathrm{C}_{3} \mathrm{~N}_{4}$ generated ROS after a single 808 $\mathrm{nm}$ laser irradiation for $5 \mathrm{~min}$. After $8 \mathrm{~min}$, the temperature exceeded $50^{\circ} \mathrm{C}$, and mice tumor growth severely decreased. Lu et $\mathrm{al}^{98}$ prepared $2 \mathrm{D} \mathrm{Ti}_{3} \mathrm{C}_{2}$ (photothermal agent) $/ \mathrm{g}-\mathrm{C}_{3} \mathrm{~N}_{4}$ heterostructure by the electrostatic assembly, which prolonged $\mathrm{g}_{-} \mathrm{C}_{3} \mathrm{~N}_{4}$ light absorption to NIR. It can produce $\mathrm{O}_{2}{ }^{--}$and $\cdot \mathrm{OH}$ under $670 \mathrm{~nm}$ for type I PDT and trigger water splitting to generate abundant $\mathrm{O}_{2}$ for type II PDT.

\section{BP}

Phosphorus atoms in the same layer of BP are connected with three other phosphorus atoms by chemical bonds, and the different layers are connected by van der Waals interaction. ${ }^{99}$ The bandgap of BP depends on the number of layers, ranging from 2.0 to $0.3 \mathrm{eV} .{ }^{100} \mathrm{BP}$ has excellent biocompatibility and strong biodegradability in vivo, indicating that BP is suitable for biomedicine. Zhang et al proved that stripped BP is an effective PS for generating ${ }^{1}$ $\mathrm{O}_{2}$ for the first time, with $0.91{ }^{1} \mathrm{O}_{2}$ quantum yield, ${ }^{101}$ 
which is far higher than those of other traditional PSs, such as porphyrin, phthalocyanine, and photodynamic nanomaterials. ${ }^{102,103}$ Modifications of improving PDT are as follows:

\section{BP Quantum Dots (BPQDs)}

Huang et $\mathrm{al}^{104}$ first synthesized BPQDs. It has good stability in physiological medium without obvious cytotoxicity. More importantly, due to the ultra-small hydrodynamic diameter $(5.4 \mathrm{~nm})$, it can be rapidly excreted from the body through kidney clearance. Song et al ${ }^{105}$ designed to embed $\mathrm{Ag}^{+}$into BPQD $(\sim 10 \mathrm{~nm})$, and the direct bandgap of $\mathrm{Ag}^{+} / \mathrm{BPQD}$ is reduced to approximately $0.1 \mathrm{eV}$, corresponding to $1300 \mathrm{~nm}$ wavelength, significantly increasing optical absorption.

\section{PS-Doped BP for PDT}

Wang et al ${ }^{106}$ prepared BP nanosheets coated with a watersoluble and positively charged AIE-PS ( $\mathrm{NH}_{2}$-PEG-TTPy), which not only works on the biocompatibility and physiological strength of BP nanosheets but also has solid fluorescence outflow at $672 \mathrm{~nm}$ and PDT capacity under 808 $\mathrm{nm}$ NIR laser. $\mathrm{C}_{60}$ was covalently grafted onto the edge of BP nanosheets. ${ }^{107}$ Photoinduced electrons from $\mathrm{BP}$ to $\mathrm{C}_{60}$ promoted $\bullet \mathrm{OH}$ generation for type I PDT, and its stability in serum, phosphate-buffered solution, and water was significantly improved. The hybridoma inhibition rate of BP- $\mathrm{C}_{60}$ was the highest $(88.2 \%)$ compared with that of original BP $(36.6 \%)$.

\section{Combined Therapy}

$\mathrm{BP}$ has an inherent photothermal effect. Lv et $\mathrm{al}^{108}$ and Ren et $\mathrm{al}^{109}$ prepared ultra-thin BP nanosheets $(13 \mathrm{~nm})$ with UCNPs. A $980 \mathrm{~nm}$ laser can achieve a photothermal conversion efficiency of $30.84 \%$, which is substantially greater than traditional AuNPs (22.63\%) and gold nanorods (23.33\%). $\mathrm{BP}$ was mixed with additional photothermal agents by the researchers. BP@PDA-Ce ${ }_{6}^{110}$ and BP-CuS ${ }^{111}$ had photothermal conversion efficiencies of $33.2 \%$ and $62.6 \%$, respectively. The researchers also combined BP with flaky, ${ }^{112}$ biconical, ${ }^{113}$ spherical, ${ }^{114}$ and rod-shaped ${ }^{115}$ AuNPs to enhance light absorption, ${ }^{1} \mathrm{O}_{2}$ generation, and thermotherapy via local surface plasmon excitation resonance. PDT combined with chemotherapeutic agents such as DOX, ${ }^{116}$ docetaxel, ${ }^{117}$ and resveratrol ${ }^{118}$ can enhance anticancer efficacy, inhibit tumor growth, and support the temperature sensitivity and controlled release of drugs. Also, PDT of BP can be combined with gene therapy and immunotherapy. Delivering human telomerase reverse transcriptase-small interfering RNA (hTERT siRNA) is an important method of gene therapy. BP nanoparticles degrade in low $\mathrm{pH}$ and rich ROS environment, escape from acidic lysosomes by polyethyleneimine, and transfer and release siRNA into the cytoplasm for gene silencing therapy. ${ }^{119}$ Song and Yang ${ }^{120}$ loaded BP with immune adjuvant (CpGoligodeoxynucleotides), an effective adjuvant for increasing cytokine secretion by antigen presenting cells, activating T cells, and recruiting them into tumor tissues. The addition of an immune adjuvant to BP may prevent them from being eliminated from circulation. This drug generated a high ROS level under NIR, leading to the transformation of hydrophobic ROS-sensitive poly(propylene sulfide) to hydrophilic polymer, leading to disintegration.

\section{GQDs}

GQDs have excellent optical properties due to quantum limitation, ${ }^{121}$ which can be used as PDT PSs. The transverse dimension is usually less than $10 \mathrm{~nm}^{122}$ compared with traditional PSs, which has many advantages, such as good biocompatibility, high water solubility, and light stability. Surface functional groups and structural modifications have a significant impact on GQDs; hence, surface modification and structural design can improve the PDT of GQDs.

First, doping GQDs with heteroatoms N, ${ }^{123} \mathrm{Cl},{ }^{124} \mathrm{~F},{ }^{125}$ $\mathrm{Eu}, \mathrm{Ag}$, and $\mathrm{Se}^{126}$ is an effective method, which can change its electronic density and optical properties to improve ROS generation efficiency. Second, PS-doped GQDs could enhance PDT. ${ }^{127}$ integrated $\mathrm{Ce}_{6}$ into GQDs via disulfide bonds. Redox-responsive $\mathrm{Ce}_{6} / \mathrm{GQDs}$ significantly inhibited HeLa cell growth. Furthermore, GQD's combination therapy is comparable to other SCPs such as chemotherapy with DOX, ${ }^{128}$ immunotherapy, ${ }^{129}$ PTT $^{130,131}$ and numerous combined therapies, all of which have been reviewed. ${ }^{22,132}$

\section{Three-Dimensional (3D) SCPs Carbon Nanomaterials}

Fullerene $\mathrm{C}_{60}$ and its derivatives can generate ROS and have high quantum yield, which has gained the attention of researchers. Due to low solubility in aqueous solution and poor optical absorption in visible light and NIR, its application of PDT is limited. Ikeda believed that the combination of $\mathrm{C}_{60}$ derivatives and solubilizers (eg, cyclodextrin, polysaccharide, lysozyme, and liposome) not only increases its water solubilization but also enhances its permeability and 
retention effect. These water-soluble complexes $\mathrm{C}_{60}-\mathrm{C}_{70}$ have high photoinduced cytotoxicity to HeLa, HaCaT, and RAW 264.7 cells under 350-500 nm light and no cytotoxicity (light $>600 \mathrm{~nm}$ ). ${ }^{133}$ Moreover, to improve the hydrophilicity of $\mathrm{C}_{60}$, Lee et $\mathrm{al}^{134}$ prepared a composite of $\mathrm{C}_{60}$ powder and nanodiamond by simple grinding, which is a stable aqueous colloidal suspension. A part of the diamond shell carbon is oxygenated for hydrophilic property so that the complex is scattered in water and physiological media. $\mathrm{C}_{60}$-diamond causes mice tumors to shrink through rapid cell ingestion and ${ }^{1} \mathrm{O}_{2}$ generation under visible light.

\section{COF}

COF is a porous crystal material in which organic building blocks or elements $(\mathrm{C}, \mathrm{N}, \mathrm{O}, \mathrm{B})$ are connected by various covalent bonds to form $2 \mathrm{D}$ or $3 \mathrm{D}$ long-range ordered periodic structures. COF also has excellent properties ${ }^{135}$ but contains heavy metal ions. COF has many advantages of free heavy metal, relative stability, good biocompatibility, strong $\pi$ stacking conductive path, high specific surface area, and large pore volume, contributing to ROS or photon diffusion. Therefore, COF is an ideal PS candidate and shows great potential in PDT.

\section{Improving Solubility of COF}

COF's biomedical application is limited due to its large size and poor colloidal stability in aqueous solution. In 2016, Chen et al applied COF to PDT for the first time. To improve COF water dispersivity, they ${ }^{28}$ synthesized a completely conjugated 2D COP (COP-P-SO $\mathrm{S}_{3} \mathrm{H}$; Figure 9). Sulfonic acid group not only improves water dispersivity but also significantly reduces bandgap to enhance optical absorption and redshift absorption edge. Moreover, it has high quantum yield of ${ }^{1} \mathrm{O}_{2}$, which is 1.2 times that of clinically approved PS (ie, PpIX). Liu et al ${ }^{136}$ used meso-5, 10, 15, 20-four (4-hydroxybenzene) porphyrin (THPP) and perfluorosulfonic acid as connectors and then modified with carboxyl terminated polyethylene glycol (PEG5kCOOH) to prepare fluorinated nano-COP with excellent physiological stability. Even after freeze-drying treatment, there was no significant interference. Moreover, fluorinated chains of COP can effectively load $\mathrm{O}_{2}$ and significantly enhance PDT. Recently, Liu et al $^{137}$ selected bovine serum albumin as a model protein and biocompatible and water-soluble drug adjuvant and used 5,10,15,20 tetrakis(4-aminophenyl)-21H,23H-porphyrin (TAPP) and 1,3,5-triamcinolone (TFP) as building blocks to synthesize stable COF, which had uniform morphology and good colloidal stability.

\section{Adjusting Molecular Unit to Expand Conjugated Structure}

Lang et $\mathrm{al}^{138}$ reported that $\mathrm{sp}^{3}$ hybrid carbon atoms in tetraphenylmethane were connected with planar porphyrins by Schiff-base reaction to form diamond-like porphyrin-based COF (Figure 10). The photosensitive COF was not affected by the high concentration of single porphyrin unit in the structure. It has advantages of good light stability, high spectral efficiency, and good dispersibility in polystyrene. Deng et $\mathrm{al}^{139}$ used molecules that cannot generate ${ }^{1} \mathrm{O}_{2}$ by themselves to construct an expanded porous framework with high surface areas and permanent porosity. It has a $1.96 \mathrm{eV}$ bandgap, which shows excellent overlap with $\mathrm{O}_{2}{ }^{--}$, leading to a significant improvement in type I PDT.
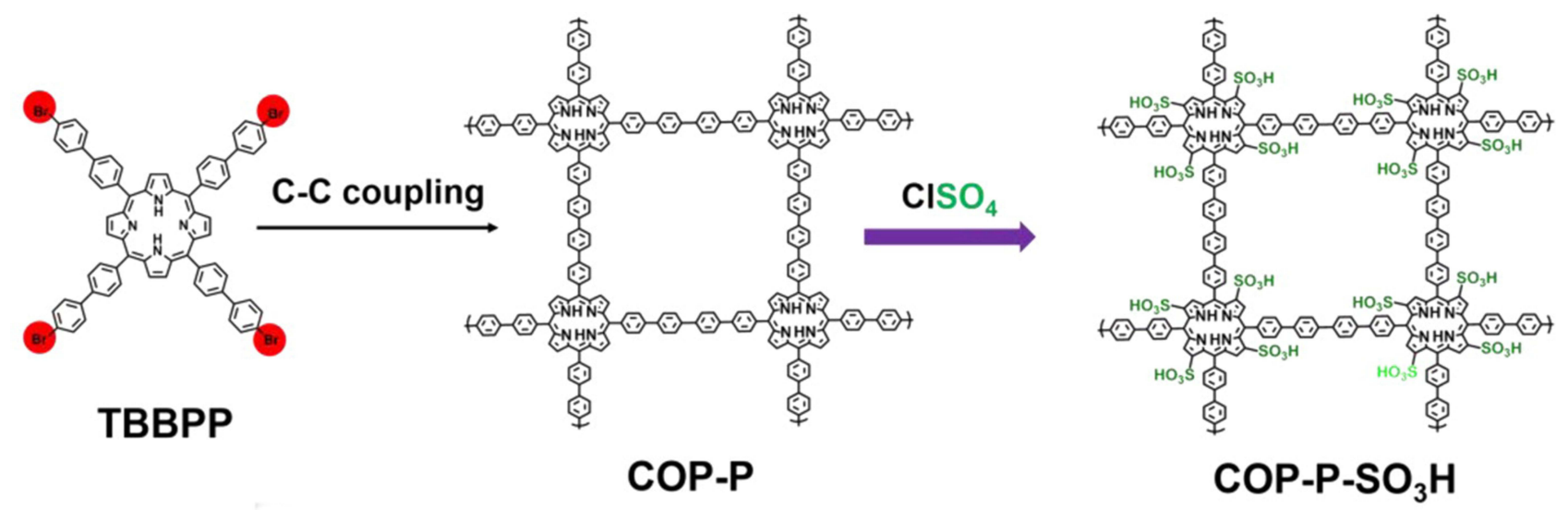

Figure 9 The scheme for synthesis of COP-P-SO ${ }_{3} \mathrm{H}$.

Notes: Reproduced with permission from: Xiang Z, Zhu L, Qi L, et al. Two-dimensional fully conjugated polymeric photosensitizers for advanced photodynamic therapy. Chem Mater. 2016;28(23):865I-8658. ${ }^{28}$ Copyright @ 2016, American Chemical Society. 


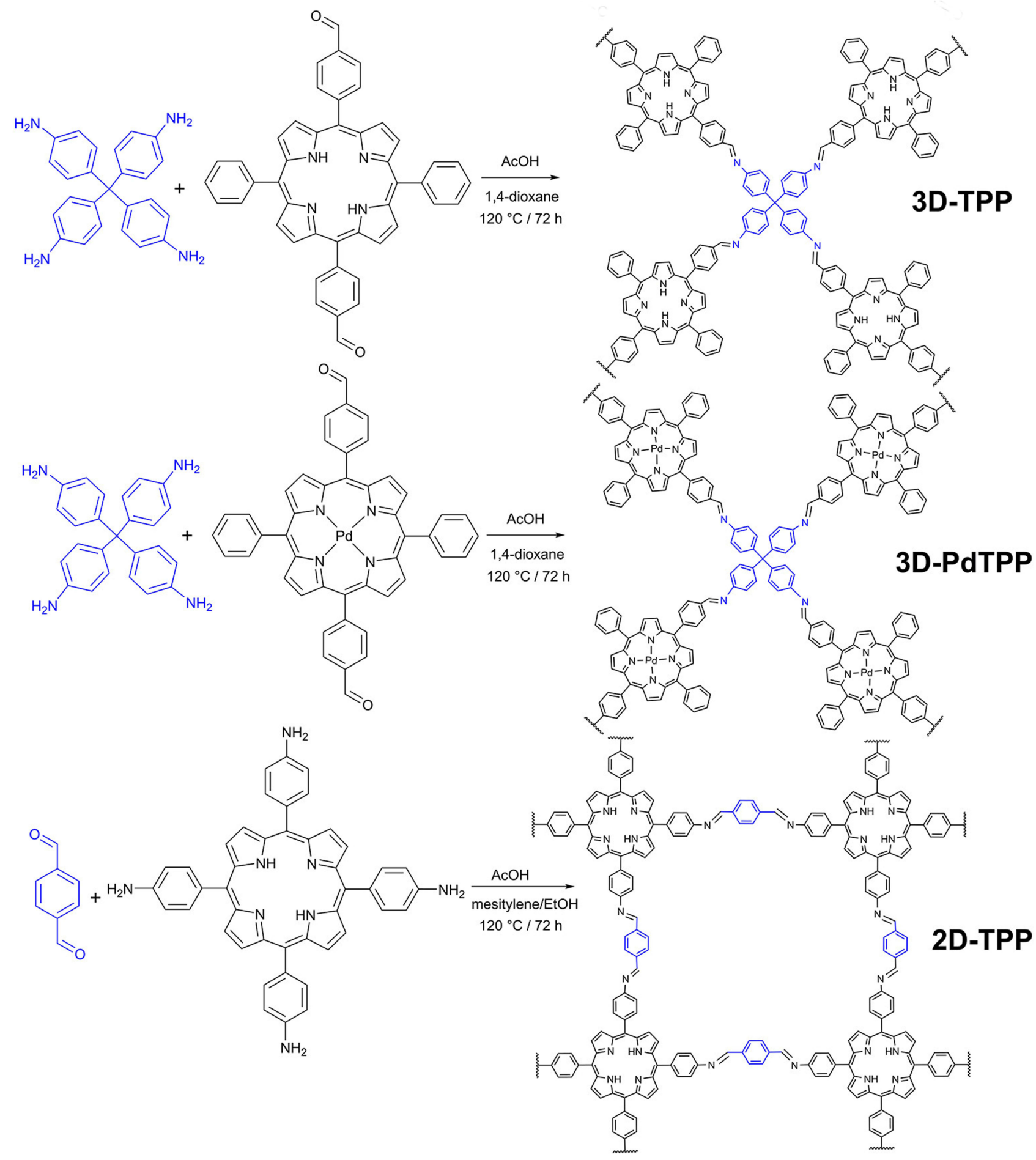

Figure 10 Syntheses of precursors and COFs (precursors of connection unit are shown in blue).

Notes: Reproduced with permission from: Hynek J, Zelenka J, Rathouský J, et al. Designing porphyrinic covalent organic frameworks for the photodynamic inactivation of

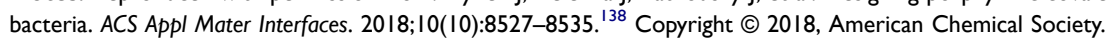

\section{PS-Doped COF}

Pan et al ${ }^{140}$ integrated dye-labeled oligonucleotides into porphyrin-based COF, which effectively quenched dye fluorescence through FRET. Compared with porphyrin monomer, the large planar structure of the electron system of COF has better stability and higher ROS generation in aqueous solution under NIR irradiation. Li et $\mathrm{al}^{141}$ reported BODIPYmodified nano-COFs $(110 \mathrm{~nm})$. Based on imino-COFs, the 
free $\mathrm{CHO}$ (bond defect in COFs) is connected with amino substituted BODIPY by Schiff-base reaction, which is beneficial for enhancing PDT. Recently, Ca-COF-BODIPY-2I is prepared. ${ }^{142}$ Covalently linked BODIPY-2I can generate ${ }^{1} \mathrm{O}_{2}$ under light, and intracellular $\mathrm{Ca}^{2+}$ overload can lead to prodeath through synergistic effect with ${ }^{1} \mathrm{O}_{2}$.

\section{Combined Therapy}

Porphyrin material has been widely studied for PDT, but its photothermal effect is rarely reported. Pang et al ${ }^{143}$ prepared porphyrin-based covalent organic polymer by solution aging at room temperature, which has high photothermal conversion efficiency $(21.7 \%)$ from $22.4^{\circ} \mathrm{C}$ to $57.5^{\circ} \mathrm{C}$ in $10 \mathrm{~min}$ and good PDT performance. Moreover, Pang et al prepared $\mathrm{COF} / \mathrm{CuSe}{ }^{144}$ and $\mathrm{COF} / \mathrm{Ag}_{2} \mathrm{Se}^{145}$ nanocomposite, which achieved enhanced therapeutic effect through a combination of PDT and PTT.

\section{Hydron-Bonded Organic Frameworks (HOFs)}

Liu et al ${ }^{146}$ designed HOFs with large p-conjugated system and four carboxylic acid groups. They have multiple hydrogen bonds, strong P-P interaction, high chemical stability, high specific surface area of $2122 \mathrm{~m}^{2} \mathrm{~g}^{-1}$, biocompatibility, and low cytotoxicity. Moreover, they have periodically integrating photoactive pyrene and can effectively encapsulate DOX for combined chemotherapy. Compared with MOFs and COFs, it has the advantages of mild synthesis conditions and good solution stability and can be used as excellent candidate materials for PDT.

\section{Issues and Strategies for Enhanced PDT \\ Oxygen Reliance}

Hypoxia is a typical pathological feature of almost all solid tumors and significantly reduces ROS generation. Type II PDT is limited by the oxygen concentration in the tumor microenvironment, which seriously restricts photodynamic efficacy. Furthermore, persistent hypoxia and damage to the vascular system can exacerbate hypoxia, eventually leading to failure of deep tumor therapy. Two methods are used to resolve hypoxia: reducing oxygen consumption and increasing oxygen generation. ${ }^{147,148}$ For hypoxia, researchers increase oxygen supply by $\mathrm{g}_{-} \mathrm{C}_{3} \mathrm{~N}_{4}$ water splitting ${ }^{149}$ and oxygen supply materials, such as $\mathrm{CeO}_{\mathrm{x}}, \mathrm{MnO}_{2}$, and catalase, to catalyze the oxidation of $\mathrm{H}_{2} \mathrm{O}_{2}$ to $\mathrm{O}_{2}$. Conversely, they can reduce $\mathrm{O}_{2}$ consumption by targeting mitochondria and inhibiting tumor cell respiration (Table 2).

First, g- $\mathrm{C}_{3} \mathrm{~N}_{4}$ bandgap was adjusted to allow its valence band to meet the requirement of $\mathrm{O}_{2}$ generation. Zhang et al ${ }^{149}$ synthesized carbon point-doped $\mathrm{g}-\mathrm{C}_{3} \mathrm{~N}_{4}$, which enhanced its red light absorption and activated water splitting in vivo. When the $\mathrm{O}_{2}$ concentration is $1 \%$, it has a good cancer cell growth inhibition effect, improves the $\mathrm{O}_{2}$ level in the tumor, and finally reverses the PDT resistance and tumor metastasis induced by hypoxia. Second, $\mathrm{O}_{2}$ supply materials, such as catalase, ${ }^{150}$ Fe-doped $\mathrm{g}_{-} \mathrm{C}_{3} \mathrm{~N}_{4}$ (similar to peroxidase), ${ }^{151}$ $\mathrm{MnO}_{2},{ }^{152}$ and $\mathrm{CeO}_{\mathrm{x}}{ }^{153}$ catalyze the oxidation of $\mathrm{H}_{2} \mathrm{O}_{2}$ to $\mathrm{O}_{2}$.

Regarding $\mathrm{BP}$, many artificial catalases, $\mathrm{Pt}$ nanoparticles, ${ }^{154-156} \mathrm{FeOCl} / \mathrm{Mn}^{2+},{ }^{157} \mathrm{Fe}-\mathrm{Pt} \mathrm{NP}^{158}$ and AuNPs ${ }^{159}$ effectively decompose the accumulated $\mathrm{H}_{2} \mathrm{O}_{2}$

Table 2 Summary of Oxygen-Generating Strategies for Tumor Oxygenation

\begin{tabular}{|c|c|c|}
\hline Materials & $\mathrm{O}_{2}$ Generation Mechanism & Reference \\
\hline$g-\mathrm{C}_{3} \mathrm{~N}_{4}$ & Water splitting & [149] \\
\hline $\mathrm{CeO}_{x}$ & $\mathrm{Ce}^{4+}$ convert $\mathrm{H}_{2} \mathrm{O}_{2}$ to $\mathrm{H}_{2} \mathrm{O}$ and $\mathrm{O}_{2}$ & [153] \\
\hline Metformin & Inhibition of the respiration of tumor cells & {$[153]$} \\
\hline Catalase & Catalytic degradation of $\mathrm{H}_{2} \mathrm{O}_{2}$ & {$[150]$} \\
\hline Fe-doped- $\mathrm{C}_{3} \mathrm{~N}_{4}$ & Catalytic degradation of $\mathrm{H}_{2} \mathrm{O}_{2}$ & {$[151]$} \\
\hline $\mathrm{MnO}_{2}$ & Catalytic degradation of $\mathrm{H}_{2} \mathrm{O}_{2}$ & [152] \\
\hline Heme & Catalytic degradation of $\mathrm{H}_{2} \mathrm{O}_{2}$ & {$[161]$} \\
\hline Pt-NPs & Catalytic degradation of $\mathrm{H}_{2} \mathrm{O}_{2}$ & {$[154,159]$} \\
\hline Au NPs & Glucose decomposition and $\mathrm{H}_{2} \mathrm{O}_{2}$ production & [158] \\
\hline $\mathrm{FeOCl}$ and $\mathrm{Mn}^{2+}$ & Catalytic degradation of $\mathrm{H}_{2} \mathrm{O}_{2}$ & {$[156]$} \\
\hline Fe-Pt NPs & Fe-based Fenton reaction & {$[157]$} \\
\hline MOF & MOF adsorption of $\mathrm{O}_{2}$ & {$[160]$} \\
\hline Cyanobacteria & Photosynthesis & [162] \\
\hline
\end{tabular}

Abbreviation: MOF, metal-organic framework. 
in the tumor and alleviate tumor hypoxia. Lei et $\mathrm{al}^{160}$ precisely encapsulated a layer of phosphorus QDs and catalase in the inner and outer layers of MOF, respectively. The outer hydrogenase transformed $\mathrm{H}_{2} \mathrm{O}_{2}$ into $\mathrm{O}_{2}$, then $\mathrm{O}_{2}$ is directly injected into the inner BP. The PDT efficiency of the drug system is 8.7 times than that without catalase. However, excessive $\mathrm{H}_{2} \mathrm{O}_{2}$ may lead to the off-target effect and change other normal biochemical processes. Ju et $\mathrm{al}^{161}$ developed a double trigger $\mathrm{O}_{2}$ self-supporting nanosystem. The BP was functionalized with a blocker DNA duplex of 50Cy5-aptamer-heme/30-heme labeled oligonucleotides. It could produce heme-dimer used to inactivate peroxidase. This system can not only enhance the stimulation effect of tumor microenvironment but also allow an 8.7-fold enhanced PDT. Recently, Huo and Shi group ${ }^{162}$ modified BP nanosheets with biocompatible photosynthetic cyanobacteria. Cyanobacteria may create $\mathrm{O}_{2}$ by photosynthesis when exposed to a $660 \mathrm{~nm}$ laser, and BPNs can activate $\mathrm{O}_{2}$ to produce ${ }^{1} \mathrm{O}_{2}$ for PDT.

\section{Light Penetration}

When light penetrates the tissue, it is absorbed or scattered, and the red light and NIR light have the greatest penetration depth $(\lambda=600-1350 \mathrm{~nm})$, usually $1-3 \mathrm{~mm}$. In the past decades, the development of penetration depth of PDT was reviewed (Table 3).

Optimizing the chemical structure of SCPs can effectively improve penetration depth. First, heteroatom-doped SCPs can achieve two-photon excitation, such as N-doped GQDs, which shows the advantages of two-photon excitation PDT and generates more ROS. ${ }^{123}$ Second, two-photon excited $g-\mathrm{C}_{3} \mathrm{~N}_{4}$ QD by reducing the size of $\mathrm{g}-\mathrm{C}_{3} \mathrm{~N}_{4}$ was developed to achieve charge transfer transformation and improve penetration depth of light. ${ }^{84}$ Third, adjusting the bandgap of SCPs can promote absorption edge redshift and enhance NIR absorption.
UCNP can convert NIR into UV and visible light. ${ }^{163}$ For example, Hsiao combined hydrophilic g- $\mathrm{C}_{3} \mathrm{~N}_{4}$ with $\mathrm{NaYF}_{4}$ : $\mathrm{Yb}^{3+} / \mathrm{Tm}^{3+}$ upconversion nanoparticles through positive ligand polylysine. UCNP can convert NIR into UV light and promote $\mathrm{g}-\mathrm{C}_{3} \mathrm{~N}_{4}$ to release blue-green visible light. ${ }^{164,165}$

Microwaves can pass through all types of tissues and induce PDT for deep cancer. Zhang et $\mathrm{al}^{85}$ reported an excellent microwave-induced $\mathrm{g}^{-} \mathrm{C}_{3} \mathrm{~N}_{4}$ QDs. In vitro cell experiment results show that $\mathrm{g}_{-} \mathrm{C}_{3} \mathrm{~N}_{4}$ QDs can enter osteosarcoma UMR-106 cells under microwave radiation and generate ${ }^{1} \mathrm{O}_{2}$, which enhances the microwave's lethal effect on tumor cells.

The Cherenkov radiation of X-ray and radionuclide can be used as internal light source, which is no longer limited by external light source penetration. The high energy of X-ray photons cannot directly excite PSs, but the highenergy ionizing radiation can be converted into UV or visible light through the energy medium (namely Cerenkov radiation), thus activating PSs. ${ }^{166}$ For example, $\mathrm{BP} / \mathrm{Bi}_{2} \mathrm{O}_{3}{ }^{167}$ and $\mathrm{Bi}_{2} \mathrm{~S}_{3}{ }^{168}$ are highly efficient and biocompatible radiosensitizers that can be used in cancer cooperative radiotherapy. When the propagation speed of dielectric charged particles produced by the decay of radionuclides (eg, $\beta^{+}$and $\beta^{-}$) is faster than that of light, Cherenkov radiation also occurs, which can emit UV and visible light $(250-600 \mathrm{~nm})$ in a wide energy range to activate PSs to generate ROS. ${ }^{88}$ However, recently, there is no relevant report on radionuclide Cherenkov radiationexcited organic SCPs, which are commonly used in $\mathrm{TiO}_{2}$ and porphyrin molecules, such as ${ }^{68} \mathrm{Ga}-\mathrm{TiO}_{2}{ }^{169}$ and ${ }^{89} \mathrm{Zr}$ porphyrin. ${ }^{170}$

The internal light source also includes chemiluminescence and bioluminescence. The chemiluminescence between luminol and hydrogen peroxide was used to activate semiconducting polymer to generate ${ }^{1} \mathrm{O}_{2}$ with good anticancer and antifungal effects. ${ }^{171}$ Furthermore, there is

Table 3 Summary of Light Penetration Strategies

\begin{tabular}{|l|c|c|}
\hline Materials & Light Penetration Mechanism & Reference \\
\hline $\mathrm{N}$-doped GQDs/adjusting g- $\mathrm{C}_{3} \mathrm{~N}_{4}$ size & Two-photon excitation & {$[84,123]$} \\
$\mathrm{g}-\mathrm{C}_{3} \mathrm{~N}_{5} / \mathrm{Zn}^{2+}$ and $\mathrm{K}^{+}$-doped $\mathrm{g}-\mathrm{C}_{3} \mathrm{~N}_{4}$ & Decrease bandgap & {$[86,87]$} \\
$\mathrm{g}-\mathrm{C}_{3} \mathrm{~N}_{4} / \mathrm{UCNPs}$ & Conversion of NIR into ultraviolet and visible light & {$[164,165]$} \\
$\mathrm{g}-\mathrm{C}_{3} \mathrm{~N}_{4} \mathrm{QDs}$ & Microwave induction & {$[85]$} \\
$\mathrm{BP} / \mathrm{Bi}_{2} \mathrm{O}_{3}$ & Cherenkov radiation of X-ray & {$[167]$} \\
$\mathrm{MEH}-\mathrm{PPV}$ & Chemiluminescence & {$[17 \mathrm{I}]$} \\
( $p$-Phenylene vinylene) derivative & Bioluminescence & {$[172]$} \\
\hline
\end{tabular}

Abbreviations: MEH-PPV, poly(2-methoxy-5-[(2-ethylhexyl)oxy]-p-phenylene vinylene); GQDs, graphene quantum dots; NIR, near-infrared; QDs, quantum dots. 
a bioluminescent resonance energy transfer between luminol and organic photovoltaics. The oligomer ( $p$-phenylene vinylene) derivative was activated by bioluminescence, which killed approximately $80 \%$ of cancer cells, and the inhibition rate of the tumor tissue was as high as $50 \%$. ${ }^{172}$

\section{Targeting}

The theoretical basis of nanomedicine is enhanced permeability and retention effect, ${ }^{173}$ that is, macromolecules larger than $40 \mathrm{kDa}$ selectively leak from tumor blood vessels and accumulate in tumor tissues, but not in normal tissues. However, recent studies have found that only $0.7 \%$ (median) of the nanoparticle injection dose reaches the tumor, ${ }^{174}$ which requires biological strategies to solve nanodrug-delivery challenge. One way to overcome tumor-delivery barrier is to pair nanodrugs with the tumor to regulate the malignant tumor microenvironment and achieve effective accumulation of nanodrugs.

First, tumor cells targeting ligands mainly include antibodies or peptides, ${ }^{14,175}$ hyaluronic acid (HA), ${ }^{158,176}$ and folic acid (FA)..$^{25,177-179}$ Ding et $\mathrm{al}^{14}$ produced a compound of photosensitizer P50 modified with HER2 antibody, demonstrating the potential of HER2-SCPNs to target SKBR-3 tumors. Feng et al ${ }^{175}$ covalently coupled surface carboxyl-modified P51 with antibody (antiEpCAM), which can detect MCF-7 tumor cells and localize them on the cell membrane, to accomplish targeted imaging of distinct regions of tumor cells. Furthermore, $\mathrm{Xu}$ et al ${ }^{180}$ modified semiconducting polymer with cyclic arginine glycine aspartate peptide, which can selectively kill $\alpha v \beta 3$ integrin-overexpressing MDA-MB-231 cells. Second, SCPs can induce subcellular organelle-mediated cell death under light, such as lysosome and mitochondria. Triphenylphosphine bromide (TPP), ${ }^{72} \mathrm{TAPP}^{181}$ and $\mathrm{Met}^{153}$ have been used as mitochondrial targeting agents for SCPs. In addition to the two abovementioned types of organelles, there are the cell membrane and nucleus, and the detailed content can be referred to other reviews. ${ }^{1}$ Lastly, in addition to biological strategies, magnetic targeting agent $\mathrm{Fe}_{3} \mathrm{O}_{4}{ }^{182,183}$ can also be used to increase PS intracellular concentration to avoid systemic toxicity.

\section{Biosafety and Toxicity Evaluations of SCPs}

The biological safety assessment of SCPs includes in vitro cellular uptake, localization, toxicity, in vivo biodistribution, degradation, excretion, material solubility, biodegradation, and biocompatibility. Metal-free SCPs essentially avoid the toxic and side effects of heavy metal ions and small molecules on organisms. The main problem of linear SCPs and high crystallinity COFs is poor hydrophilicity, which has been mentioned in the previous section and will not be repeated here.

GQDs have smaller particle size, which cannot accumulate in the main organs and are quickly removed by the kidney, showing low cytotoxicity in vitro. Recently, some studies have evaluated the photodynamic cytotoxicity of GQDs in vitro and in vivo. ${ }^{22}$ To further improve the solubility of GQDs, $\mathrm{Li}$ and Yi combined GQDs with PEG to improve its solubility and blood circulation. ${ }^{184}$

Block g- $\mathrm{C}_{3} \mathrm{~N}_{4}$ has high stability, which makes it difficult to dissolve and biodegrade. To meet the requirements of practical clinical application, it needs to be modified. The most common method is preparation of ultra-thin $\mathrm{g}$ $\mathrm{C}_{3} \mathrm{~N}_{4}$ nanosheets or PEG modification. ${ }^{185}$ Xie analyzed the viability of HeLa cells after incubation for $48 \mathrm{~h}$ by MTT and found that ultra-thin $\mathrm{g}-\mathrm{C}_{3} \mathrm{~N}_{4}$ nanoplates had excellent biocompatibility. When the $\mathrm{g}-\mathrm{C}_{3} \mathrm{~N}_{4}$ nanoplate concentration is as high as $600 \mu \mathrm{g} \mathrm{mL} \mathrm{m}^{-1}$, there was no significant loss of cell viability. ${ }^{186}$

The BP stability is poor when compared to other SCPs. In vivo, $\mathrm{BP}$ is biodegradable and creates nontoxic and biocompatible intermediates, such as phosphate and phosphite, that are suitable for biomedical applications. ${ }^{187}$ The cytotoxicity of BP on L-929 fibroblasts was evaluated by Han et al ${ }^{188}$ in terms of dosage and duration. The findings revealed that BP cytotoxicity was proportional to concentration and exposure duration and influenced by decreasing enzyme activity and membrane damage mediated by oxidative stress. There was no apparent cytotoxicity when the BP concentration was less than $4 \mathrm{~g} \mathrm{~mL}^{-1}$. When BP comes into touch with oxygen, light, or water, interstitial oxygen will be incorporated, resulting in massive structural deformation. ${ }^{189}$ As a result, it is necessary to modify its surface to prevent rapid degradation. For example, graphene, h-BN, ${ }^{187} \mathrm{PEG},{ }^{190} \mathrm{Al}_{2} \mathrm{O}_{3},{ }^{191}$ titanium sulfonate ligand $\left(\mathrm{TiL}_{4}\right),{ }^{192}$ aryl diazonium salt ${ }^{193}$ and other surface coating methods can significantly increase stability and minimize degradation.

\section{Conclusions}

This review describes the research progress of the application of metal-free organic conjugated polymer for PDT. SCPs as PSs have good optical properties, such as high photostability and easy surface functionalization. Progress has been achieved in the application of SCPs in phototherapy, and some issues have been discussed, such as hypoxia, low 
permeability, targeting, biocompatibility, and safety. However, there are still some important issues to be solved.

1. The research of 2D and 3D SCPs for PDT, such as covalent triazine framework and HOF, is still in the early stage. Inspired by linear polymers, D-A structures of 2D and 3D SCPs can be designed. Optimization of material synthesis, high yield, surface functionalization, size, morphology, defects, heterojunction, and multifunctional composites could help improve ROS generation efficiency. Furthermore, modification of metal ions leads to pollution; thus, the concentration should be controlled in a clear range.

2. SCPs are large, and molecular weight is not single, so we need to further explore QDs and self-assembly of oligomers; balance surface functionalization, polymer size, and concentration; and prolong the action time of drugs in vivo. The operating parameters of in vitro and in vivo studies, such as irradiation intensity, irradiation time and drug dose, and injection mode, need to be normalized to facilitate control studies.

3. The combination of PDT with gene therapy, radiotherapy, photothermal therapy, chemotherapy, and sonodynamic therapy needs further exploration. PDT can also achieve accurate diagnosis and realtime evaluation of therapeutic efficiency through imaging. However, there is an obvious contradiction between the efficiency of multifunctional composites and PDT, for example, the absorption efficiency of light, binding mode (nonspecific binding, covalent binding and indirect covalent binding through biomolecular bridge), and load rate of drugs on SCPs. Therefore, we need to establish standards to balance various factors.

4. Most studies did not consider the potential effects of drugs on stem, red blood, and immune cells. Moreover, we need to consider the differences between mouse models and large mammalian and human tumors. Human tumors are rarely exposed like xenograft mouse models. Presently, the biosafety research on SCPs is still in the early stage. There are no toxicity studies on systemic biodistribution, tolerance threshold, degradation, and clearance rate to determine the long-term effects of potential toxicity on animals. Therefore, it is urgent to conduct more comprehensive physical and chemical properties (residual harmful solvents in the synthesis process), nanoscience, and biosafety toxicity assessment of SCPs.

In conclusion, in view of the development of SCPs and new emerging technologies in the future for PDT improvement, it is believed that PDT will be recognized as an effective therapy in clinical cancer.

\section{Abbreviations}

AIE, aggregation-induced emission; BP, black phosphorus; $\mathrm{BPQD}, \mathrm{BP}$ quantum dots; $\mathrm{COF}$, covalent organic framework; CTF, covalent triazine framework; EC, edge of the conduction; EV, edge of the valence; FA, folic acid; FRET, fluorescence resonance energy transfer; GQD, graphene quantum dots; HOF, hydron-bonded organic frameworks; HOMO, highest occupied molecular orbital; ISC, intersystem crossing; LUMO, lowest unoccupied molecular orbital; MOF, metal-organic framework; PS, photosensitizers; $\mathrm{QD}$, quantum dots; ROS, reactive oxygen species; SCPs, semiconducting conjugated polymers.

\section{Consent for Publication}

The authors confirm that the details of any images can be published.

\section{Author Contributions}

All authors made a significant contribution to the work reported, whether that is in the conception, study design, execution, acquisition of data, analysis and interpretation, or in all these areas; took part in drafting, revising or critically reviewing the article; gave final approval of the version to be published; have agreed on the journal to which the article has been submitted; and agree to be accountable for all aspects of the work.

\section{Funding}

This work was supported by the Science and Technology Innovation Enhancement Project of Army Medical University (No: 2018XLC3042).

\section{Disclosure}

The authors report no conflicts of interest for this work.

\section{References}

1. Hu JJ, Lei Q, Zhang X-Z. Recent advances in photonanomedicines for enhanced cancer photodynamic therapy. Prog Mater Sci. 2020;114:100685.doi:10.1016/j.pmatsci.2020.100685 
2. Zhang G, Lan ZA, Wang X. Conjugated polymers: catalysts for photocatalytic hydrogen evolution. Angew Chem Int. 2016;55 (51):15712-15727. doi:10.1002/anie.201607375

3. Wu W, Bazan GC, Liu B. Conjugated-polymer-amplified sensing, imaging, and therapy. Chem. 2017;2(6):760-790. doi:10.1016/j. chempr.2017.05.002

4. Fu X, Bai H, Lyu F, Liu L, Wang S. Conjugated polymer nanomaterials for phototherapy of cancer. Chem Res Chin Univ. 2020;36(2):237-242. doi:10.1007/s40242-020-0012-7

5. Meng Z, Hou W, Zhou H, Zhou L, Chen H, Wu C. Therapeutic considerations and conjugated polymer-based photosensitizers for photodynamic. Therapy Macromol Rapid Commun. 2018;39(5). doi:10.1002/marc.201700614

6. Zuo J, Tu L, Li Q, et al. Near infrared light sensitive ultravioletblue nanophotoswitch for imaging-guided "off-on" therapy. ACS Nano. 2018;12(4):3217-3225. doi:10.1021/acsnano.7b07393

7. Martynenko IV, Kuznetsova VA, Orlova AO, et al. Chlorin e6-ZnSe/ZnS quantum dots based system as reagent for photodynamic therapy. Nanotechnology. 2015;26(5):055102. doi:10.1088/0957-4484/26/5/055102

8. Qi ZD, Li DW, Jiang P, Jiang FL, Cheah C. Biocompatible CdSe quantum dot-based photosensitizer under two-photon excitation for photodynamic therapy. J Mater Chem. 2011;21(8):2455-2458.

9. Jiang Y, Pu K. Multimodal biophotonics of semiconducting polymer nanoparticles. Acc Chem Res. 2018;51(8):1840-1849. doi:10.1021/acs.accounts. 8 b00242

10. Lan M, Zhao S, Xie Y, et al. Water-soluble polythiophene for two-photon excitation fluorescence imaging and photodynamic therapy of cancer. ACS Appl Mater Interfaces. 2017;9 (17):14590-14595. doi:10.1021/acsami.6b15537

11. Guo L, Ge J, Liu Q, et al. Versatile polymer nanoparticles as two-photon-triggered photosensitizers for simultaneous cellular, deep-tissue imaging, and photodynamic therapy. Adv Healthcare Mater. 2017;6(12):1601431. doi:10.1002/adhm.201601431

12. Han HH, Wang CZ, Zang Y, Li J, James TD, He XP. Supramolecular core-glycoshell polythiophene nanodots for targeted imaging and photodynamic therapy. Chem Commun. 2017;53(70):9793-9796. doi:10.1039/C7CC04525E

13. Wu $\mathrm{P}, \mathrm{Xu} \mathrm{N}$, Tan $\mathrm{C}$, et al. Light-induced translocation of a conjugated polyelectrolyte in cells: from fluorescent probe to anticancer agent. ACS Appl Mater Interfaces. 2017;9 (12):10512-10518. doi:10.1021/acsami.7b00540

14. Feng G, Fang Y, Liu J, Geng J, Ding D, Liu B. Multifunctional conjugated polymer nanoparticles for image-guided photodynamic and photothermal therapy. Small. 2017;13(3):1602807. doi:10.1002/smll.201602807

15. Zheng Z, Jia Z, Qin Y, et al. All-in-one zeolite-carbon-based nanotheranostics with adjustable NIR-II window photoacoustic/ fluorescence imaging performance for precise NIR-II photothermal-synergized catalytic antitumor therapy. Small. 2021;17 (41):2103252. doi:10.1002/smll.202103252

16. Li R, Niu R, Qi J, et al. Conjugated polythiophene for rapid, simple, and high-throughput screening of antimicrobial photosensitizers. ACS Appl Mater Interfaces. 2015;7 (27):14569-14572. doi:10.1021/acsami.5b04552

17. Yuan H, Zhan Y, Rowan AE, Xing C, Kouwer PHJ. Biomimetic networks with enhanced photodynamic antimicrobial activity from conjugated polythiophene/polyisocyanide hybrid hydrogels. Angew Chem Int. 2020;59(7):2720-2724. doi:10.1002/anie.201910979

18. Tabata Y, Murakami Y, Ikada Y. Photodynamic effect of polyethylene glycol-modified fullerene on tumor. Jpn $J$ Cancer Res. 1997;88(11):1108-1116. doi:10.1111/j.13497006.1997.tb00336.x

19. Chen Y, Tan C, Zhang H, Wang L. Two-dimensional graphene analogues for biomedical applications. Chem Soc Rev. 2015;44 (9):2681-2701. doi:10.1039/C4CS00300D
20. Luo Y, Li Z, Zhu C, et al. Graphene-like metal-free 2D nanosheets for cancer imaging and theranostics. Trends Biotechnol. 2018;36 (11):1145-1156. doi:10.1016/j.tibtech.2018.05.012

21. Chen J, Wu W, Zhang F, et al. Graphene quantum dots in photodynamic therapy. Nanoscale Adv. 2020;2(10):4961-4967. doi:10.1039/D0NA00631A

22. Fan HY, Yu XH, Wang $\mathrm{K}$, et al. Graphene quantum dots (GQDs)-based nanomaterials for improving photodynamic therapy in cancer treatment. Eur J Med Chem. 2019;182:111620. doi:10.1016/j.ejmech.2019.111620

23. MacFarlane LR, Shaikh H, Garcia-Hernandez JD, Vespa M, Fukui T, Manners I. Functional nanoparticles through $\pi$ conjugated polymer self-assembly. Nat Rev Mater. 2021;6:7-26. doi:10.1038/s41578-020-00233-4

24. Xue F, Shi M, Yan Y, Yang H, Zhou Z, Yang S. Iridium complex loaded polypyrrole nanoparticles for NIR laser induced photothermal effect and generation of singlet oxygen. RSC Adv. 2016;6 (19):15509-15512. doi:10.1039/C5RA22092K

25. Xing C, Liu L, Tang H, et al. Design guidelines for conjugated polymers with light-activated anticancer activity. Adv Funct Mater. 2011;21(21):4058-4067. doi:10.1002/adfm.201100840

26. Mao D, Liu J, Ji S, et al. Amplification of near-infrared fluorescence in semiconducting polymer nanoprobe for grasping the behaviors of systemically administered endothelial cells in ischemia treatment. Biomaterials. 2017;143:109-119. doi:10.1016/j. biomaterials.2017.07.038

27. He F, Ren X, Shen X, Xu Q-H. Water-soluble conjugated polymers for amplification of one- and two-photon properties of photosensitizers. Macromolecules. 2011;44(13):5373-5380. doi: $10.1021 / \mathrm{ma} 2008805$

28. Xiang Z, Zhu L, Qi L, et al. Two-dimensional fully conjugated polymeric photosensitizers for advanced photodynamic therapy. Chem Mater. 2016;28(23):8651-8658. doi:10.1021/acs. chemmater.6b03619

29. Chen D, Yu Q, Huang X, et al. A highly-efficient type I photosensitizer with robust vascular-disruption activity for hypoxic-and-metastatic tumor specific photodynamic therapy. Small. 2020;16:2001059. doi:10.1002/smll.202001059

30. Rahman M, Tian H, Edvinsson T. Revisiting the limiting factors for overall water-splitting on organic photocatalysts. Angew Chem Int. 2020;59(38):16278-16293. doi:10.1002/anie.202002561

31. She $\mathrm{X}, \mathrm{Wu} J, \mathrm{Xu} \mathrm{H}$, et al. High efficiency photocatalytic water splitting using 2D $\alpha-\mathrm{Fe}_{2} \mathrm{O}_{3} / \mathrm{g}-\mathrm{C}_{3} \mathrm{~N}_{4}$ Z-scheme catalysts. $A d v$ Energy Mater. 2017;7(17):1700025. doi:10.1002/aenm.201700025

32. Mo Z, Di J, Yan P, et al. An all-organic D-a system for visible-light-driven overall water splitting. Small. 2020;16(48): e2003914. doi:10.1002/smll.202003914

33. Sarmah CP. Microstructure and optical properties of ultra thin film of gold nanocomposite polyaniline. Indian $J$ Pure Appl Phys. 2016;54:401-405.

34. Pesant S, Boulanger $P$, Côté $M$, et al. Ab initio study of ladder-type polymers polythiophene and polypyrrole. Chem Phys Lett. 2006;450:329-334. doi:10.1016/j.cplett.2007.11.023

35. Hariharan A, Subramanian K, Alagar M, Dinakaran K. Conjugated donor-acceptor copolymers derived from phenylenevinylene and tri substituted pyridine units: synthesis, optical and electrochemical properties. High Perform Polym. 2014;27 (6):724-733. doi:10.1177/0954008314559312

36. Hou Q, Xu X, Guo T, Zeng X, Luo S, Yang L. Synthesis and photovoltaic properties of fluorene-based copolymers with narrow band-gap units on the side chain. Eur Polym J. 2010;46 (12):2365-2371. doi:10.1016/j.eurpolymj.2010.09.015

37. Atwani O, Baristiran C, Erden A, Sonmez G. A stable, low band gap electroactive polymer: poly(4,7-dithien-2-yl-2,1,3-benzothiadiazole). Synth Met. 2008;158(3-4):83-89. doi:10.1016/j. synthmet.2007.12.013 
38. Ge B, Wei Q, Sun A, et al. A 3D iodoplumbate semiconducting open framework with visible-light-induced photocatalytic performance. Chem Asian J. 2019;14(12):2086-2090. doi:10.1002/asia.201900392

39. Shaktawat V, Jain N, Saxena R, Saxena NS, Sharma TP. Electrical conductivity and optical band gap studies of polypyrrole doped with different acids. Optoelectron Adv Mater Rapid Commun. 2007;9:2130-2132.

40. Ji E, Corbitt TS, Parthasarathy A, Schanze KS, Whitten DG. Light and dark-activated biocidal activity of conjugated polyelectrolytes. ACS Appl Mater Interfaces. 2011;3 (8):2820-2829. doi:10.1021/am200644g

41. Bingshe X, Peide H, Liping W, et al. Optical properties in 2D photonic crystal structure using fullerene and azafullerene thin films. Opt Commun. 2005;250(1-3):120-125. doi:10.1016/j. optcom.2005.02.017

42. Li S, Wang P, Zhao H, Wang R, Li Z. Fabrication of black phosphorus nanosheets/BiOBr visible light photocatalysts via the co-precipitation method. Colloids Surf a Physicochem Eng Aspects. 2020;612:125967. doi:10.1016/j.colsurfa.2020.125967

43. Wen J, Xie J, Chen X, Li X. A review on $\mathrm{g}_{-} \mathrm{C}_{3} \mathrm{~N}_{4}$-based photocatalysts. Appl Surf Sci. 2017;391:72-123. doi:10.1016/j. apsusc.2016.07.030

44. Ma X, Pang C, Li S, et al. Synthesis of Zr-coordinated amide porphyrin-based two-dimensional covalent organic framework at liquid-liquid interface for electrochemical sensing of tetracycline. Biosens Bioelectron. 2019;146:111734. doi:10.1016/j. bios.2019.111734

45. Foote CS. Definition of type I and type II photosensitized oxidation. Photochem Photobiol. 1991;54(5):659. doi:10.1111/ j.1751-1097.1991.tb02071.x

46. Sheu C, Kang P, Khan S, Foote CS. Low-temperature photosensitized oxidation of a guanosine derivative and formation of an imidazole ring-opened product. J Am Chem Soc. 2002;124 (15):3905-3913. doi:10.1021/ja011696e

47. Liao JC, Roider J, Jay DG. Chromophore-assisted laser inactivation of proteins is mediated by the photogeneration of free radicals. Proc Natl Acad Sci US A. 1994;91(7):2659-2663. doi:10.1073/pnas.91.7.2659

48. Huang Y, Pappas HC, Zhang L, et al. Selective imaging and inactivation of bacteria over mammalian cells by imidazolium-substituted polythiophene. Chem Mater. 2017;29 (15):6389-6395. doi:10.1021/acs.chemmater.7b01796

49. Lichon L, Kotras C, Myrzakhmetov B, et al. Polythiophenes with cationic phosphonium groups as vectors for imaging, siRNA delivery, and photodynamic therapy. Nanomaterials. 2020;10 (8):1432. doi:10.3390/nano10081432

50. Wang B, Yuan $\mathrm{H}$, Zhu C, et al. Polymer-drug conjugates for intracellar molecule-targeted photoinduced inactivation of protein and growth inhibition of cancer cells. Sci Rep. 2012;2:766. doi:10.1038/srep00766

51. Khatoon SS, Chen Y, Zhao H, Lv F, Liu L, Wang S. In situ self-assembly of conjugated polyelectrolytes for cancer targeted imaging and photodynamic therapy. Biomater Sci. 2020;8 (8):2156-2163. doi:10.1039/C9BM01912J

52. Schmidt K, Brovelli S, Coropceanu V, et al. Intersystem crossing processes in nonplanar aromatic heterocyclic molecules. J Phys Chem A. 2007;111(42):10490. doi:10.1021/jp075248q

53. Cekli S, Winkel RW, Schanze KS. Effect of oligomer length on photophysical properties of platinum acetylide donor-acceptordonor oligomers. J Phys Chem A. 2016;120(28):5512-5521. doi:10.1021/acs.jpca.6b03977

54. Zhou W, Chen Y, Zhang Y, et al. Iodine-rich semiconducting polymer nanoparticles for CT/fluorescence dual-modal imaging-guided enhanced photodynamic therapy. Small. 2020;16 (5):e1905641. doi:10.1002/smll.201905641
55. Cekli S, Winkel RW, Alarousu E, Mohammed OF, Schanze KS Triplet excited state properties in variable gap $\pi$-conjugated donor-acceptor-donor chromophores. Chem Sci. 2016;7 (6):3621-3631. doi:10.1039/C5SC04578A

56. $\mathrm{Xu} \mathrm{S}, \mathrm{Wu} \mathrm{W}$, Cai X, et al. Highly efficient photosensitizers with aggregation-induced emission characteristics obtained through precise molecular design. Chem Commun. 2017;53 (62):8727-8730. doi:10.1039/C7CC04864E

57. Wang S, Wu W, Manghnani P, et al. Polymerization-enhanced two-photon photosensitization for precise photodynamic therapy. ACS Nano. 2019;13(3):3095-3105. doi:10.1021/ acsnano. 8 b08398

58. Feng G, Zhang GQ, Ding D. Design of superior phototheranostic agents guided by Jablonski diagrams. Chem Soc Rev. 2020;49 (22):8179-8234. doi:10.1039/D0CS00671H

59. Yang T, Liu L, Deng $Y$, et al. Ultrastable near-infrared conjugated-polymer nanoparticles for dually photoactive tumor inhibition. Adv Mater. 2017;29(31):1700487. doi:10.1002/ adma.201700487

60. Zhang X, Zhang A, Feng J, et al. A heavy atom free semiconducting polymer with high singlet oxygen quantum yield for photodynamic and photothermal synergistic therapy. Mater Des. 2021;197:109263. doi:10.1016/j.matdes.2020.109263

61. Wang H, Guo L, Wang Y, Feng L. Bactericidal activity-tunable conjugated polymers as a human-friendly bactericide for the treatment of wound infections. Biomater Sci. 2019;7 (9):3788-3794. doi:10.1039/C9BM00695H

62. Hu L, Chen Z, Liu Y, et al. In vivo bioimaging and photodynamic therapy based on two-photon fluorescent conjugated polymers containing dibenzothiophene-S,S-dioxide derivatives. ACS Appl Mater Interfaces. 2020;12(51):57281-57289. doi:10.1021/acsami.0c12955

63. Hu L, Zhang Y, Guo T, Ying L, Xiong J, Yang W. Synthesis and properties of blue-light-emitting Oligo(fluorene-codibenzothiophene-S,S-dioxide)s. Dyes Pigments. 2019;166:502-514. doi:10.1016/j.dyepig.2019.03.059

64. Zhai L, Zhang Z, Zhao Y, Tang Y. Efficient antibacterial performance and effect of structure on property based on cationic conjugated polymers. Macromolecules. 2018;51(18):7239-7247. doi:10.1021/acs.macromol.8b01530

65. Liu S, Zhang H, Li Y, et al. Strategies to enhance the photosensitization: polymerization and the donor-acceptor even-odd effect. Angew Chem Int. 2018;57(46):15189-15193. doi:10.1002/anie. 201810326

66. Wu M, Wu L, Li J, et al. Self-luminescing theranostic nanoreactors with intraparticle relayed energy transfer for tumor microenvironment activated imaging and photodynamic therapy. Theranostics. 2019;9(1):20-33. doi:10.7150/thno.28857

67. Zhang Z, Cao Y, Zhu X, Li Y, Cai X. Zwitterionic conjugated polymer as the single component for photoacoustic-imaging-guided dual-modal near-infrared phototherapy. ACS Biomater Sci Eng. 2020;6(7):4005-4011. doi:10.1021/acsbiomaterials.0c00206

68. Chang K, Tang Y, Fang X, Yin S, Xu H, Wu C. Incorporation of porphyrin to $\pi$-conjugated backbone for polymer-dot-sensitized photodynamic therapy. Biomacromolecules. 2016;17 (6):2128-2136. doi:10.1021/acs.biomac.6b00356

69. Xing $\mathrm{C}, \mathrm{Xu} \mathrm{Q}$, Tang H, Liu L, Wang S. Conjugated polymer/ porphyrin complexes for efficient energy transfer and improving light-activated antibacterial activity. J Am Chem Soc. 2009;131 (36):13117-13124. doi:10.1021/ja904492x

70. Li S, Chang K, Sun K, et al. Amplified singlet oxygen generation in semiconductor polymer dots for photodynamic cancer therapy. ACS Appl Mater Interfaces. 2016;8(6):3624-3634. doi:10.1021/ acsami.5b07995 
71. Sprick RS, Jiang JX, Bonillo B, et al. Tunable organic photocatalysts for visible-light-driven hydrogen evolution. $\mathrm{J} \mathrm{Am} \mathrm{Chem}$ Soc. 2015;137(9):3265-3270. doi:10.1021/ja511552k

72. Yao H, Dai J, Zhuang Z, et al. Red AIE conjugated polyelectrolytes for long-term tracing and image-guided photodynamic therapy of tumors. Sci China Chem. 2020;63(12):1815-1824. doi:10.1007/s11426-020-9824-2

73. Huang Y, Qiu F, Shen L, et al. Combining two-photon-activated fluorescence resonance energy transfer and near-infrared photothermal effect of unimolecular micelles for enhanced photodynamic therapy. ACS Nano. 2016;10(11):10489-10499. doi:10.1021/acsnano.6b06450

74. Moan J, Berg K. The photodegradation of porphyrins in cells can be used to estimate the lifetime of singlet oxygen. Photochem Photobiol. 1991;53(4):549-553. doi:10.1111/j.1751-1097.1991. tb03669.x

75. Yuan Y, Liu J, Liu B. Conjugated-polyelectrolyte-based polyprodrug: targeted and image-guided photodynamic and chemotherapy with on-demand drug release upon irradiation with a single light source. Angew Chem Int. 2014;53(28):7163-7168. doi:10.1002/anie.201402189

76. Cui D, Huang J, Zhen X, Li J, Jiang Y, Pu K. A semiconducting polymer nano-prodrug for hypoxia-activated photodynamic cancer therapy. Angew Chem Int. 2019;58(18):5920-5924. doi:10.1002/anie.201814730

77. Qian C, Yu J, Chen Y, et al. Light-activated hypoxia-responsive nanocarriers for enhanced anticancer therapy. Adv Mater. 2016;28 (17):3313-3320. doi:10.1002/adma.201505869

78. Zeng Z, Zhang C, Li J, Cui D, Jiang Y, Pu K. Activatable polymer nanoenzymes for photodynamic immunometabolic cancer therapy. Adv Mater. 2020;33:e2007247. doi:10.1002/ adma.202007247

79. Zhu H, Fang Y, Miao Q, et al. Regulating near-infrared photodynamic properties of semiconducting polymer nanotheranostics for optimized cancer therapy. ACS Nano. 2017;11(9):8998-9009. doi:10.1021/acsnano.7b03507

80. Liang $\mathrm{Y}$, Zhang $\mathrm{H}$, Yuan $\mathrm{H}$, et al. Conjugated polymer and triphenylamine derivative codoped nanoparticles for photothermal and photodynamic antimicrobial therapy. ACS Appl Bio Mater. 2020;3(6):3494-3499. doi:10.1021/acsabm.0c00320

81. Liao G, He F, Li Q, et al. Emerging graphitic carbon nitride-based materials for biomedical applications. Prog Mater Sci. 2020;112:100666. doi:10.1016/j.pmatsci.2020.100666

82. Hu T, Mei X, Wang Y, Weng X, Liang R, Wei M. Twodimensional nanomaterials: fascinating materials in biomedical field. Sci Bull. 2019;64(22):1707-1727. doi:10.1016/j. scib.2019.09.021

83. Zhou Z, Song J, Nie L, Chen X. Reactive oxygen species generating systems meeting challenges of photodynamic cancer therapy. Chem Soc Rev. 2016;45(23):6597-6626.

84. Wu X, Yang L, Luo L, Shi G, Wei X, Wang F. Engineered g-C 3 N 4 quantum dots for tunable two-photon imaging and photodynamic therapy. ACS Appl Bio Mater. 2019;2(5):1998-2005. doi:10.1021/acsabm.9b00055

85. Chu X, Li K, Guo H. Exploration of graphitic-C3N4 quantum dots for microwave induced photodynamic therapy. ACS Biomater Sci Eng. 2017;2:1998-2005.

86. Liu X, Xing S, Xu Y, Chen R, Lin C, Guo L. 3-Amino-1,2,4-triazole-derived graphitic carbon nitride for photodynamic therapy. Spectrochim Acta A Mol Biomol Spectrosc. 2021;250:119363. doi:10.1016/j.saa.2020.119363

87. Wu Y, Yang D, Xu W, et al. Tunable water-soluble carbon nitride by alkali-metal cations modification: enhanced ROS-evolving and adsorption band for photodynamic therapy. Appl Cat B. 2020;269:118848. doi:10.1016/j.apcatb.2020.118848
88. Ong WJ, Tan LL, Ng YH, Yong ST, Chai SP. Graphitic carbon nitride $\left(\mathrm{g}-\mathrm{C}_{3} \mathrm{~N}_{4}\right)$-based photocatalysts for artificial photosynthesis and environmental remediation: are we a step closer to achieving sustainability? Chem Rev. 2016;116(12):7159-7329. doi:10.1021/ acs.chemrev.6b00075

89. Wang H, Lin Q, Yin L, et al. Biomimetic design of hollow flower-like g- $\mathrm{C}_{3} \mathrm{~N}_{4} @$ PDA organic framework nanospheres for realizing an efficient photoreactivity. Small. 2019;15(16): e1900011. doi:10.1002/smll.201900011

90. Huang YF, Zhang M, Zhao LB, Feng JM, Wu DY. Activation of oxygen on gold and silver nanoparticles assisted by surface plasmon resonances. Angew Chem Int Ed. 2014;126:2353-2357. doi:10.1002/anie.201310097

91. Dai J, Song J, Qiu Y, et al. Gold nanoparticle-decorated $g-\mathrm{C}_{3} \mathrm{~N}_{4}$ nanosheets for controlled generation of reactive oxygen species upon $670 \mathrm{~nm}$ laser illumination. ACS Appl Mater Interfaces. 2019;11(11):10589-10596. doi:10.1021/acsami.9b01307

92. Chan CF, Zhou Y, Guo H, et al. pH-dependent cancer-directed photodynamic therapy by a water-soluble graphitic-phase carbon nitride-porphyrin nanoprobe. ChemPlusChem. 2016;81 (6):535-540. doi:10.1002/cplu.201600085

93. Huang Q, Chen Y, Hao L, et al. Pegylated carbon nitride nanosheets for enhanced reactive oxygen species generation and photodynamic therapy under hypoxic conditions. Nanomedicine. 2020;25:102167. doi:10.1016/j.nano.2020.102167

94. Li RQ, Zhang C, Xie BR, et al. A two-photon excited $\mathrm{O} 2$-evolving nanocomposite for efficient photodynamic therapy against hypoxic tumor. Biomaterials. 2019;194:84-93. doi:10.1016/j.biomaterials.2018.12.017

95. Lin LS, Cong ZX, Li J, et al. Graphitic-phase C3N4 nanosheets as efficient photosensitizers and $\mathrm{pH}$-responsive drug nanocarriers for cancer imaging and therapy. $J$ Mater Chem B. 2014;2 (8):1031-1037. doi:10.1039/c3tb21479f

96. Chen R, Zhang J, Wang Y, Chen X, Zapien JA, Lee CS. Graphitic carbon nitride nanosheet@metal-organic framework core-shell nanoparticles for photo-chemo combination therapy. Nanoscale. 2015;7(41):17299-17305. doi:10.1039/C5NR04436G

97. Huang Y, Tian Y, Shu J, Wang F, Wei X. Oxygen self-enriched single-component "black carbon nitride" for near-infrared phototheranostics. Nanoscale. 2020;12(42):21812-21820. doi:10.1039/ D0NR05871H

98. Zhang Y, Cheng Y, Yang F, et al. Near-infrared triggered $\mathrm{Ti}_{3} \mathrm{C}_{2} /$ g- $\mathrm{C}_{3} \mathrm{~N}_{4}$ heterostructure for mitochondria-targeting multimode photodynamic therapy combined photothermal therapy. Nano Today. 2020;34:100919. doi:10.1016/j.nantod.2020.100919

99. Kou L, Chen C, Smith SC. Phosphorene: fabrication, properties, and applications. J Phys Chem Lett. 2015;6(14):2794-2805. doi:10.1021/acs.jpclett.5b01094

100. Xu Y, Wang Z, Guo Z, et al. Solvothermal synthesis and ultrafast photonics of black phosphorus quantum dots. Adv Opt Mater. 2016;4(8):1223-1229. doi:10.1002/adom.201600214

101. Wang H, Yang X, Shao W, et al. Ultrathin black phosphorus nanosheets for efficient singlet oxygen generation. $\mathrm{J} \mathrm{Am} \mathrm{Chem}$ Soc. 2015;137(35):11376-11382. doi:10.1021/jacs.5b06025

102. Chen J, Fan T, Xie Z, et al. Advances in nanomaterials for photodynamic therapy applications: status and challenges. Biomaterials. 2020;237:119827. doi:10.1016/j.biomaterials.20 20.119827

103. Tian J, Huang B, Nawaz MH, Zhang W. Recent advances of multi-dimensional porphyrin-based functional materials in photodynamic therapy. Coord Chem Rev. 2020;420:213410. doi:10.1016/j.ccr.2020.213410

104. Guo T, Wu Y, Lin Y, et al. Black phosphorus quantum dots with renal clearance property for efficient photodynamic therapy. Small. 2018;14(4):1702815. doi:10.1002/ smll.201702815 
105. Li Z, Fu Q, Ye J, et al. $\mathrm{Ag}^{+}$-coupled black phosphorus vesicles with emerging NIR-II photoacoustic imaging performance for cancer immune-dynamic therapy and fast wound healing. Angew Chem Int. 2020;59(49):22202-22209. doi:10.1002 anie. 202009609

106. Huang J, He B, Zhang Z, et al. Aggregation-induced emission luminogens married to $2 \mathrm{D}$ black phosphorus nanosheets for highly efficient multimodal theranostics. Adv Mater. 2020;32 (37):e2003382. doi:10.1002/adma.202003382

107. Liu Y, Zhu D, Zhu X, et al. Enhancing the photodynamic therapy efficacy of black phosphorus nanosheets by covalently grafting fullerene C60. Chem Sci. 2020;11(42):11435-11442. doi:10.1039/ D0SC03349A

108. Xu D, Liu J, Wang Y, Jian Y, Wu W, Lv R. Black phosphorus nanosheet with high thermal conversion efficiency for photodynamic/photothermal/immunotherapy. ACS Biomater Sci Eng. 2020;6(9):4940-4948. doi:10.1021/acsbiomaterials.0c00984

109. Dibaba ST, Wei R, Xi W, et al. Theranostic nanocomposite from upconversion luminescent nanoparticles and black phosphorus nanosheets. RSC Adv. 2018;8(62):35706-35718. doi:10.1039/ C8RA07441K

110. Yang X, Wang D, Zhu J, et al. Functional black phosphorus nanosheets for mitochondria-targeting photothermal/photodynamic synergistic cancer therapy. Chem Sci. 2019;10 (13):3779-3785. doi:10.1039/C8SC04844D

111. Jana D, Jia S, Bindra AK, Xing P, Ding D, Zhao Y. Clearable black phosphorus nanoconjugate for targeted cancer phototheranostics. ACS Appl Mater Interfaces. 2020;12 (16):18342-18351. doi:10.1021/acsami.0c02718

112. Yang D, Yang G, Yang P, et al. Assembly of Au plasmonic photothermal agent and iron oxide nanoparticles on ultrathin black phosphorus for targeted photothermal and photodynamic cancer therapy. Adv Funct Mater. 2017;27(18):1700371. doi:10.1002/adfm.201700371

113. Wang J, Zhang H, Xiao X, et al. Gold nanobipyramid-loaded black phosphorus nanosheets for plasmon-enhanced photodynamic and photothermal therapy of deep-seated orthotopic lung tumors. Acta Biomater. 2020;107:260-271. doi:10.1016/j. actbio.2020.03.001

114. Zhang D, Lin X, Lan S, et al. Localized surface plasmon resonance enhanced singlet oxygen generation and light absorption based on black phosphorus@AuNPs nanosheet for tumor photodynamic/thermal therapy. Part Part Syst Char. 2018;35 (4):1800010. doi:10.1002/ppsc.201800010

115. Zheng T, Zhou T, Feng X, Shen J, Zhang M, Sun Y. Enhanced Plasmon-Induced Resonance Energy Transfer (PIRET)-mediated photothermal and photodynamic therapy guided by photoacoustic and magnetic resonance imaging. ACS Appl Mater Interfaces. 2019;11(35):31615-31626. doi:10.1021/acsami.9b09296

116. Xu M, Yang $\mathrm{G}, \mathrm{Bi} \mathrm{H}$, et al. An intelligent nanoplatform for imaging-guided photodynamic/photothermal/chemo-therapy based on upconversion nanoparticles and $\mathrm{CuS}$ integrated black phosphorus. Chem Eng J. 2020;382:122822. doi:10.1016/j. cej.2019.122822

117. Li R, Shan L, Yao Y, et al. Black phosphorus nanosheets and docetaxel micelles co-incorporated thermoreversible hydrogel for combination chemo-photodynamic therapy. Drug Deliv Transl Res. 2021;11(3):1133-1143. doi:10.1007/s13346-020-00836-y

118. Hai L, Zhang A, Wu X, et al. Liposome-stabilized black phosphorus for photothermal drug delivery and oxygen self-enriched photodynamic therapy. ACS Appl Nano Mater. 2019;3:563-575. doi:10.1021/acsanm.9b02119

119. Chen L, Chen C, Chen W, et al. Biodegradable black phosphorus nanosheets mediate specific delivery of hTERT siRNA for synergistic cancer therapy. ACS Appl Mater Interfaces. 2018;10 (25):21137-21148. doi:10.1021/acsami.8b04807
120. Li L, Yang Z, Fan W, et al. In situ polymerized hollow mesoporous organosilica biocatalysis nanoreactor for enhancing ROS-mediated anticancer therapy. Adv Funct Mater. 2020;30 (4):1905758. doi:10.1002/adfm.201905758

121. Zheng XT, Ananthanarayanan A, Luo KQ, et al. Glowing graphene quantum dots and carbon dots: properties, syntheses, and biological applications. Small. 2015;11(14):1620-1636. doi:10.1002/smll.201402648

122. Yan Y, Gong J, Chen J, et al. Recent advances on graphene quantum dots: from chemistry and physics to applications. $A d v$ Mater. 2019;31:1808283. doi:10.1002/adma.201808283

123. Kuo WS, Yeh TS, Chang CY, et al. Amino-functionalized nitrogen-doped graphene quantum dots for efficient enhancement of two-photon-excitation photodynamic therapy: functionalized nitrogen as a bactericidal and contrast agent. Int J Nanomedicine. 2020;15:6961-6973. doi:10.2147/IJN.S242892

124. Wang L, Li Y, Wang Y, et al. Chlorine-doped graphene quantum dots with enhanced anti- and pro-oxidant properties. ACS Appl Mater Interfaces. 2019;11(24):21822-21829. doi:10.1021/ acsami.9b03194

125. Li Z, Wang D, Xu M, et al. Fluorine-containing graphene quantum dots with a high singlet oxygen generation applied for photodynamic therapy. J Mater Chem B. 2020;8(13):2598-2606. doi:10.1039/C9TB02529D

126. Roeinfard M, Zahedifar M, Darroudi M, Khorsand Zak A, Sadeghi E. Synthesis of graphene quantum dots decorated with $\mathrm{Se}, \mathrm{Eu}$ and $\mathrm{Ag}$ as photosensitizer and study of their potential to use in photodynamic therapy. J Fluoresc. 2021;31(2):551-557. doi:10.1007/s10895-020-02674-0

127. Du D, Wang K, Wen Y, Li Y, Li YY. Photodynamic graphene quantum dot: reduction condition regulated photoactivity and size dependent efficacy. ACS Appl Mater Interfaces. 2016;8 (5):3287-3294. doi:10.1021/acsami.5b11154

128. Ju J, Regmi S, Fu A, Lim S, Liu Q. Graphene quantum dot based charge-reversal nanomaterial for nucleus-targeted drug delivery and efficiency controllable photodynamic therapy. J Biophotonics. 2019;12(6):e201800367. doi:10.1002/jbio.201800367

129. Wu C, Guan X, Xu J, et al. Highly efficient cascading synergy of cancer photo-immunotherapy enabled by engineered graphene quantum dots/photosensitizer/CpG oligonucleotides hybrid nanotheranostics. Biomaterials. 2019;205:106-119. doi:10.1016/ j.biomaterials.2019.03.020

130. Cao Y, Dong H, Yang Z, et al. Aptamer-conjugated graphene quantum dots/porphyrin derivative theranostic agent for intracellular cancer-related MicroRNA detection and fluorescence-guided photothermal/photodynamic synergetic therapy. ACS Appl Mater Interfaces. 2017;9(1):159-166. doi:10.1021/acsami.6b13150

131. Yu Y, Mei L, Shi Y, et al. Ag-Conjugated graphene quantum dots with blue light-enhanced singlet oxygen generation for ternary-mode highly-efficient antimicrobial therapy. $J$ Mater Chem B. 2020;8(7):1371-1382. doi:10.1039/C9TB02300C

132. Tade RS, Patil PO. Theranostic prospects of graphene quantum dots in breast cancer. ACS Biomater Sci Eng. 2020;6 (11):5987-6008. doi:10.1021/acsbiomaterials.0c01045

133. Antoku D, Sugikawa K, Ikeda A. Photodynamic activity of fullerene derivatives solubilized in water by natural-product-based solubilizing agents. Chemistry. 2019;25(8):1854-1865. doi:10.1002/chem.201803657

134. Lee H, Seok lee JS, Moor KJ, et al. Hand-ground fullerene-nanodiamond composite for photosensitized water treatment and photodynamic cancer therapy. $J$ Colloid Interface Sci. 2021;587:101-109. doi:10.1016/j.jcis.2020.12.020

135. Zheng X, Wang L, Pei Q, He S, Liu S, Xie Z. Metal-organic framework@porous organic polymer nanocomposite for photodynamic therapy. Chem Mater. 2017;29(5):2374-2381. doi:10.1021/acs.chemmater.7b00228 
136. Tao Y, Chan HF, Shi B, Li M, Leong KW. Light: a magical tool for controlled drug delivery. Adv Funct Mater. 2020;30 (49):1804901. doi:10.1002/adfm.202005029

137. Sun T, Xia R, Zhou J, Zheng X, Liu S, Xie Z. Protein-assisted synthesis of nanoscale covalent organic frameworks for phototherapy of cancer. Mater Chem Front. 2020;4(8):2346-2356. doi:10.1039/D0QM00274G

138. Hynek J, Zelenka J, Rathouský J, et al. Designing porphyrinic covalent organic frameworks for the photodynamic inactivation of bacteria. ACS Appl Mater Interfaces. 2018;10(10):8527-8535. doi:10.1021/acsami.7b19835

139. Zhang L, Wang S, Zhou Y, Wang C, Zhang XZ, Deng H. Covalent organic frameworks as favorable constructs for photodynamic therapy. Angew Chem Int. 2019;58(40):14213-14218. doi:10.1002/anie.201909020

140. Gao P, Wang M, Chen Y, et al. A COF-based nanoplatform for highly efficient cancer diagnosis, photodynamic therapy and prognosis. Chem Sci. 2020;11(26):6882-6888. doi:10.1039/ DoSC00847H

141. Guan Q, Fu DD, Li YA, et al. BODIPY-decorated nanoscale covalent organic frameworks for photodynamic therapy. iScience. 2019;14:180-198. doi:10.1016/j.isci.2019.03.028

142. Guan Q, Zhou LL, Lv FH, Li WY, Li YA, Dong YB. A glycosylated covalent organic framework equipped with BODIPY and $\mathrm{CaCO}_{3}$ for synergistic tumor therapy. Angew Chem Int. 2020;59 (41):18042-18047. doi:10.1002/anie.202008055

143. Shi Y, Liu S, Liu Y, et al. Facile fabrication of nanoscale porphyrinic covalent organic polymers for combined photodynamic and photothermal cancer therapy. ACS Appl Mater Interfaces. 2019;11(13):12321-12326. doi:10.1021/acsami.9b00361

144. Hu C, Zhang Z, Liu S, Liu X, Pang M. Monodispersed CuSe sensitized covalent organic framework photosensitizer with an enhanced photodynamic and photothermal effect for cancer therapy. ACS Appl Mater Interfaces. 2019;11(26):23072-23082. doi:10.1021/acsami.9b08394

145. Hu C, Cai L, Liu S, Pang M. Integration of a highly monodisperse covalent organic framework photosensitizer with cation exchange synthesized Ag2Se nanoparticles for enhanced phototherapy. Chem Commun. 2019;55(62):9164-9167. doi:10.1039/C9CC04668B

146. Yin Q, Zhao P, Sa R, et al. An ultra-robust and crystalline redeemable hydrogen-bonded organic framework for synergistic chemo-photodynamic therapy. Angew Chem Int Ed. 2018;57 (26):7691-7696. doi:10.1002/anie.201800354

147. Zhang C, Qin W-J, Bai X-F, Zhang X-Z. Nanomaterials to relieve tumor hypoxia for enhanced photodynamic therapy. Nano Today. 2020;35:100960. doi:10.1016/j.nantod.2020.100960

148. Sahu A, Kwon I, Tae G. Improving cancer therapy through the nanomaterials-assisted alleviation of hypoxia. Biomaterials. 2020;228:119578. doi:10.1016/j.biomaterials.2019.119578

149. Zheng DW, Li B, Li CX, et al. Carbon-dot-decorated carbon nitride nanoparticles for enhanced photodynamic therapy against hypoxic tumor via water splitting. ACS Nano. 2016;10 (9):8715-8722. doi:10.1021/acsnano.6b04156

150. Zhao $\mathrm{H}$, Li L, Zheng $\mathrm{C}$, et al. An intelligent dual stimuli-responsive photosensitizer delivery system with $\mathrm{O}_{2}$-supplying for efficient photodynamic therapy. Colloids Surf $B$ Biointerfaces. 2018;167:299-309. doi:10.1016/j.colsurfb.20 18.04 .011

151. Ma Z, Zhang M, Jia X, et al. FeIII -doped two-dimensional C3 N4 nanofusiform: a new $\mathrm{O}_{2}$-evolving and mitochondria-targeting photodynamic agent for MRI and enhanced antitumor therapy. Small. 2016;12(39):5477-5487. doi:10.1002/smll.201601681
152. Zhang $\mathrm{W}, \mathrm{Li} \mathrm{S}$, Liu $\mathrm{X}$, et al. Oxygen-generating $\mathrm{MnO}_{2}$ nanodots-anchored versatile nanoplatform for combined chemo-photodynamic therapy in hypoxic cancer. Adv Funct Mater. 2018;28(13):1706375. doi:10.1002/adfm.201706375

153. Jiang W, Zhang $\mathrm{C}$, Ahmed A, et al. $\mathrm{H}_{2} \mathrm{O}_{2}$-sensitive upconversion nanocluster bomb for tri-mode imaging-guided photodynamic therapy in deep tumor tissue. Adv Healthc Mater. 2019;8(20): e1900972. doi:10.1002/adhm.201900972

154. Ouyang J, Deng Y, Chen W, et al. Marriage of artificial catalase and black phosphorus nanosheets for reinforced photodynamic antitumor therapy. J Mater Chem B. 2018;6(14):2057-2064. doi:10.1039/C8TB00371H

155. Yang X, Liu R, Zhong Z, et al. Platinum nanoenzyme functionalized black phosphorus nanosheets for photothermal and enhanced-photodynamic therapy. Chem Eng J. 2021;409:127381. doi:10.1016/j.cej.2020.127381

156. Lan S, Lin Z, Zhang D, Zeng Y, Liu X. Photocatalysis enhancement for programmable killing of hepatocellular carcinoma through self-compensation mechanisms based on black phosphorus quantum-dot-hybridized nanocatalysts. ACS Appl Mater Interfaces. 2019;11(10):9804-9813. doi:10.1021/acsami.8b21820

157. Zhang Y, Xu M, Wang Y, Toledo F, Zhou F. Studies of metal ion binding by apo-metallothioneins attached onto preformed self-assembled monolayers using a highly sensitive surface plasmon resonance spectrometer. Sens Actuators B Chem. 2007;123 (2):784-792, 127491. doi:10.1016/j.snb.2006.10.019

158. Yao X, Yang B, Wang S, et al. A novel multifunctional FePt/BP nanoplatform for synergistic photothermal/photodynamic/chemodynamic cancer therapies and photothermally-enhanced immunotherapy. J Mater Chem B. 2020;8(35):8010-8021. doi:10.1039/D0TB00411A

159. Cai L, Hu C, Liu S, Zhou Y, Pang M, Lin J. A covalent organic framework-based multifunctional therapeutic platform for enhanced photodynamic therapy via catalytic cascade reactions. Sci China Mater. 2020;64:488-497. doi:10.1007/s40843-020-1428-0

160. Liu J, Liu T, Du P, Zhang L, Lei J. Metal-organic framework (MOF) hybrid as a tandem catalyst for enhanced therapy against hypoxic tumor cells. Angew Chem Int. 2019;58(23):7808-7812. doi:10.1002/anie.201903475

161. Liu J, Du P, Mao H, Zhang L, Ju H, Lei J. Dual-triggered oxygen self-supply black phosphorus nanosystem for enhanced photodynamic therapy. Biomaterials. 2018;172:83-91. doi:10.1016/j. biomaterials.2018.04.051

162. Qi F, Ji P, Chen Z, et al. Photosynthetic cyanobacteria-hybridized black phosphorus nanosheets for enhanced tumor photodynamic therapy. Small. 2021;17(42):2102113. doi:10.1002/ smll.202102113

163. Jiang L, Yang J, Zhou S, et al. Strategies to extend near-infrared light harvest of polymer carbon nitride photocatalysts. Coord Chem Rev. 2021;439:213947.

164. Chan MH, Chen CW, Lee IJ, et al. Near-infrared light-mediated photodynamic therapy nanoplatform by the electrostatic assembly of upconversion nanoparticles with graphitic carbon nitride quantum dots. Inorg Chem. 2016;55(20):10267-10277. doi:10.1021/ acs.inorgchem.6b01522

165. Feng L, He F, Yang G, et al. NIR-driven graphitic-phase carbon nitride nanosheets for efficient bioimaging and photodynamic therapy. J Mater Chem B. 2016;4(48):8000-8008. doi:10.1039/C6TB02232D

166. Zou X, Yao M, Ma L, et al. X-ray-induced nanoparticle-based photodynamic therapy of cancer. Nanomedicine. 2014;9 (15):2339-2351. doi:10.2217/nnm.13.198 
167. Huang $\mathrm{H}$, He L, Zhou W, et al. Stable black phosphorus $/ \mathrm{Bi}_{2} \mathrm{O}_{3}$ heterostructures for synergistic cancer radiotherapy. Biomaterials. 2018;171:12-22. doi:10.1016/j.biomaterials.2018.04.022

168. Luo K, Wu H, Chen Y, et al. Preparation of Bi-based hydrogel for multi-modal tumor therapy. Colloids Surf B Biointerfaces. 2021;200:111591. doi:10.1016/j.colsurfb.2021.111591

169. Duan D, Liu H, Xu Y, et al. Activating TiO2 nanoparticles: gallium-68 serves as a high-yield photon emitter for cerenkov-induced photodynamic therapy. ACS Appl Mater Interfaces. 2018;10(6):5278-5286. doi:10.1021/acsami.7b17902

170. Yu B, Ni D, Rosenkrans ZT, Barnhart TE, Cai W. A "missiledetonation" strategy to precisely supply and efficiently amplify cerenkov radiation energy for cancer theranostics. Adv Mater. 2019;31(52):1904894. doi:10.1002/adma.201904894

171. Zhang Y, Pang L, Ma C, et al. Small molecule-initiated light-activated semiconducting polymer dots: an integrated nanoplatform for targeted photodynamic therapy and imaging of cancer cells. Anal Chem. 2014;86(6):3092-3099. doi:10.1021/ ac404201s

172. Yuan H, Chong H, Wang B, et al. Chemical molecule-induced light-activated system for anticancer and antifungal activities. $J \mathrm{Am}$ Chem Soc. 2012;134(32):13184-13187. doi:10.1021/ja304986t

173. Wang Y, Feng L, Wang S. Conjugated polymer nanoparticles for imaging, cell activity regulation, and therapy. Adv Funct Mater 2019;29(5):1806818. doi:10.1002/adfm.201806818

174. Wilhelm S, Tavares AJ, Dai Q, et al. Analysis of nanoparticle delivery to tumours. Nat Rev Mater. 2016;1(5):16014. doi:10.1038/natrevmats.2016.14

175. Feng L, Zhu J, Wang Z. Biological functionalization of conjugated polymer nanoparticles for targeted imaging and photodynamic killing of tumor cells. ACS Appl Mater Interfaces. 2016;8 (30):19364-19370. doi:10.1021/acsami.6b06642

176. Li Y, Feng P, Wang C, Miao W, Huang H. Black phosphorus nanophototherapeutics with enhanced stability and safety for breast cancer treatment. Chem Eng J. 2020;400:125851. doi:10.1016/j.cej.2020.125851

177. Zhang W, Dang G, Dong J, et al. A multifunctional nanoplatform based on graphitic carbon nitride quantum dots for imaging-guided and tumor-targeted chemo-photodynamic combination therapy. Colloids Surf B Biointerfaces. 2020;199:111549. doi:10.1016/j.colsurfb.2020.111549

178. Fan J, Fang G, Zeng F, Wang X, Wu S. Water-dispersible fullerene aggregates as a targeted anticancer prodrug with both chemo- and photodynamic therapeutic actions. Small. 2013;9 (4):613-621. doi:10.1002/smll.201201456

179. Wang J, Liang D, Qu Z, Kislyakov IM, Kiselev VM, Liu J. PEGylated-folic acid-modified black phosphorus quantum dots as near-infrared agents for dual-modality imaging-guided selective cancer cell destruction. Nanophotonics. 2020;9 (8):2425-2435. doi:10.1515/nanoph-2019-0506

180. Jin G, He R, Liu Q, et al. Theranostics of triple-negative breast cancer based on conjugated polymer nanoparticles. ACS Appl Mater Interfaces. 2018;10(13):10634-10646. doi:10.1021/ acsami.7b14603

International Journal of Nanomedicine

\section{Publish your work in this journal}

The International Journal of Nanomedicine is an international, peerreviewed journal focusing on the application of nanotechnology in diagnostics, therapeutics, and drug delivery systems throughout the biomedical field. This journal is indexed on PubMed Central, MedLine, CAS, SciSearch ${ }^{\mathbb{R}}$, Current Contents ${ }^{\mathbb{B}} /$ Clinical Medicine, $^{2}$
181. Lu Y, Song G, He B, et al. Strengthened tumor photodynamic therapy based on a visible nanoscale covalent organic polymer engineered by microwave assisted synthesis. Adv Funct Mater. 2020;30:2004834. doi:10.1002/adfm.202004834

182. Cheng HL, Guo HL, Xie AJ, Shen YH, Zhu MZ. 4-in-1 $\mathrm{Fe}_{3} \mathrm{O}_{4} /$ g- $\mathrm{C}_{3} \mathrm{~N}_{4} @$ PPy-DOX nanocomposites: magnetic targeting guided trimode combinatorial chemotherapy/PDT/PTT for cancer. $J \quad$ Inorg Biochem. 2021;215:111329. doi:10.1016/j. jinorgbio.2020.111329

183. Zeng S, Gao H, Li C, et al. Boosting photothermal theranostics via TICT and molecular motions for photohyperthermia therapy of muscle-invasive bladder cancer. Adv Healthc Mater. 2021: e2101063. doi:10.1002/adhm.202101063

184. Zhang X, Li H, Yi C, et al. Host immune response triggered by graphene quantum-dot-mediated photodynamic therapy for oral squamous cell carcinoma. Int $J$ Nanomedicine. 2020;15:9627-9638. doi:10.2147/IJN.S276153

185. Feng L, He F, Liu B, et al. g-C3N4 coated upconversion nanoparticles for $808 \mathrm{~nm}$ near-infrared light triggered phototherapy and multiple imaging. Chem Mater. 2016;28(21):7935-7946. doi:10.1021/acs.chemmater.6b03598

186. Zhang X, Xie X, Wang H, Zhang J, Pan B, Xie Y. Enhanced photoresponsive ultrathin graphitic-phase C3N4 nanosheets for bioimaging. J Am Chem Soc. 2013;135(1):18-21. doi:10.1021/ ja308249k

187. Anju S, Ashtami J, Mohanan PV. Black phosphorus, a prospective graphene substitute for biomedical applications. Mater Sci Eng C Mater Biol Appl. 2019;97:978-993. doi:10.1016/j. msec.2018.12.146

188. Song S-J, Shin Y, Lee H, Kim B, Han DW, Lim D. Dose- and time-dependent cytotoxicity of layered black phosphorus in fibroblastic cells. Nanomaterials. 2018;8(6):408. doi:10.3390/ nano8060408

189. Wang G, Pandey R, Karna SP. Phosphorene oxide: stability and electronic properties of a novel two-dimensional material. Nanoscale. 2014;7(2):524-531. doi:10.1039/C4NR05384B

190. Han C, Hu Z, Gomes LC, et al. Surface functionalization of black phosphorus via potassium toward high-performance complementary devices. Nano Lett. 2017;17(7):4122-4129. doi:10.1021/acs. nanolett.7b00903

191. Autere A, Ryder CR, Säynätjoki A, et al. Rapid and large-area characterization of exfoliated black phosphorus using third-harmonic generation microscopy. $J$ Phys Chem Lett. 2017;8(7):1343-1350. doi:10.1021/acs.jpclett.7b00140

192. Qu G, Liu W, Zhao Y, et al. Improved biocompatibility of black phosphorus nanosheets by chemical modification. Sci Found China. 2018;56:14488-14493.

193. Ryder CR, Wood JD, Wells SA, et al. Covalent functionalization and passivation of exfoliated black phosphorus via aryl diazonium chemistry. Nat Chem. 2016;8(6):597-602. doi:10.1038/ nchem. 2505

Journal Citation Reports/Science Edition, EMBase, Scopus and the Elsevier Bibliographic databases. The manuscript management system is completely online and includes a very quick and fair peer-review system, which is all easy to use. Visit http://www.dovepress.com/ testimonials.php to read real quotes from published authors. 